\title{
Modulation of the Pacific Decadal Oscillation on the summer precipitation over East China: a comparison of observations to 600-years control run of Bergen Climate Model
}

\author{
Lei Yu • Tore Furevik • Odd Helge Otterå • \\ Yongqi Gao
}

Received: 13 July 2013/Accepted: 10 April 2014/Published online: 1 May 2014

(C) The Author(s) 2014. This article is published with open access at Springerlink.com

\begin{abstract}
Observations show that the summer precipitation over East China often goes through decadal variations of opposite sign over North China and the Yangtze River valley (YRV), such as the "southern flood and northern drought" pattern that occurred during the late 1970s1990s. In this study it is shown that a modulation of the Pacific Decadal Oscillation (PDO) on the summer precipitation pattern over East China during the last century is partly responsible for this characteristic precipitation pattern. During positive PDO phases, the warm winter sea surface temperatures (SSTs) in the eastern subtropical Pacific along the western coast of North American propagate to the tropics in the following summer due to weakened oceanic meridional circulation and the existence of a coupled wind-evaporation-SST feedback mechanism, resulting in a warming in the eastern tropical Pacific Ocean
\end{abstract}

L. Yu $(\bowtie) \cdot$ T. Furevik

Geophysical Institute, University of Bergen, Bergen, Norway

e-mail: yulei@mail.iap.ac.cn

L. Yu

Climate Changes Research Center, Institute of Atmospheric

Physics, Chinese Academy of Sciences, Beijing 100029, China

T. Furevik · O. H. Otterå · Y. Gao

Bjerknes Centre for Climate Research, Bergen, Norway

O. H. Otterå

Uni Climate, Uni Research, Bergen, Norway

Y. Gao

Nansen Environmental and Remote Sensing Center,

Bergen, Norway

Y. Gao

Nansen-Zhu International Research Centre, Institute of Atmospheric Physics, Chinese Academy of Sciences, Beijing 100029, China $\left(5^{\circ} \mathrm{N}-20^{\circ} \mathrm{N}, 160^{\circ} \mathrm{W}-120^{\circ} \mathrm{W}\right)$ in summer. This in turn causes a zonal anomalous circulation over the subtropicaltropical Pacific Ocean that induces a strengthened western Pacific subtropical high (WPSH) and thus more moisture over the YRV region. The end result of these events is that the summer precipitation is increased over the YRV region while it is decreased over North China. The suggested mechanism is found both in the observations and in a 600-years fully coupled pre-industrial multi-century control simulations with Bergen Climate Model. The intensification of the WPSH due to the warming in the eastern tropical Pacific Ocean was also examined in idealized SSTA-forced AGCM experiments.

Keywords Summer precipitation pattern - Pacific Decadal Oscillation - Sea surface temperature anomalies . Western Pacific subtropical high

\section{Introduction}

East Asia is confined by the North Pacific Ocean to the east and southeast, the Indian Ocean to the southwest, the Tibetan Plateau in the northwest, and the East-Siberian Lowland to the north. These regions all influence the climate over the East Asia on many different temporal and spatial scales, for instance through various natural variability modes and teleconnection patterns such as PDO (Mantua et al. 1997; Deser et al. 2004) and El NiñoSouthern Oscillation (ENSO, e.g., Wang et al. 2000; Lau and Weng 2001; Wu et al. 2003). The East Asian Summer Monsoon (EASM) is the most important component of the East Asian climate system and thus plays a key role for societies and ecosystems. The EASM carries large amounts of water vapor into the region, contributing as much as 
$40-50$ and $60-70 \%$ of the annual precipitation over South and North China, respectively (Gong 2007). Observations show that the EASM weakened from the late 1970s to the late 1990s (Hu and Yang 2003). At the same time the summer precipitation increased over the Yangtze River valley YRV region and decreased over North China, a pattern often referred to as the "Southern Flood and Northern Drought" pattern in the public. In this study this particular precipitation pattern is referred to as the "YRV Flood and Northern Drought" (YFND) rather than "Southern Flood and Northern Drought" in order to avoid confusion.

Substantial efforts have been made in order to pin down the causes of the characteristic YFND pattern, and several potential mechanisms have been put forward. Some studies have pointed to the role of tropical sea surface temperature anomalies (SSTAs), where a warming in the Niño-3.4 region is believed to have contributed to the weakening of the EASM after the 1970s (Wang 2001). Also, the late twentieth century summer warming over the Indian Ocean and the western tropical Pacific Ocean and the associated intensification and westward extension of WPSH may be key for understanding the decadal trend in precipitation over the YRV region (e.g., Hu 1997; Gong and Ho 2002; He and Gong 2002; Zhou et al. 2009a). Some studies have also attributed the YFND pattern to the weakening of the EASM (e.g., Li et al. 2010; Zhou et al. 2013; Qian and Zhou 2013), but the causes for the weakening trend of the EASM during last several decades have yet to be firmly established, although various forcing mechanisms have been suggested. These include for instance the tropical ocean warming (e.g., Li et al. 2010), the role of aerosol forcing (e.g., Xu 2001; Menon et al. 2002; Wang et al. 2013), Tibetan Plateau forcing (Ding et al. 2008), and stratosphere-troposphere interactions ( $\mathrm{Yu}$ et al. 2004; Yu and Zhou 2007). A detailed review can be found in Zhou et al. (2009b).

As an alternative explanation, several studies have shown the possible impacts from PDO on the East Asian summer precipitation after 1970s. For instance, it has been suggested that during periods when the PDO and ENSO are in phase, the precipitation over southern China tends to be below normal (Johnny and Zhou 2005). More direct links between the PDO and the precipitation pattern have also been documented. For instance, Yang and Lau (2004) found a relationship between the positive PDO and the downward trend of the summer precipitation over North China. Ma (2007) also reported an anti-correlation between the PDO and the precipitation in North China based on surface wetness index, showing that the positive phase of PDO matches drought periods in North China and vice versa. Other model studies (e.g., Li et al. 2010) have suggested that the warming in the central-eastern tropical
Pacific Ocean during positive PDO years in the late 1970s1990s was a major cause for the weakening of the EASM and the associated YFND pattern. Moreover Zhu et al. (2011) found that summer precipitation over eastern China has changed after year 2000, with a decrease over the YRV region and an increase over the central part of North China. Zhu et al. (2011) attributed these precipitation changes to the warming over the Lake Baikal and the weakened westerly winds probably induced by the negative PDO after year 2000. More recent studies have also highlighted the possible modulation of the PDO on EASM and the associated summer precipitation changes. For examples, Zhou et al. (2013) showed an anti-correlation between the EASM and the PDO since 1950, where a negative phase of the PDO corresponds to a stronger EASM and more precipitation in North China. Similar correlations between positive PDO and aridity over North China have also been reported in some studies for the period 1900-2010 (e.g., Qian and Zhou 2013; Yu 2013). However these studies were mainly based on observations. If the mechanism for the linkage between the PDO on the decadal variability of summer precipitation over East China can also be identified and verified in long-term coupled climate model simulations, this would be an important contribution to help us better understand the decadal climate variability over the East Asia. Therefore, it is necessary to further explore the mechanism behind the link between the PDO and summer precipitation over East China through dedicated modeling experiments.

In this study, an observation-based analysis of the potential linkage between PDO and the EASM is made, and results from a 600-year control run of Bergen Climate Model (BCM), as well as results from dedicated SSTAforcing experiments are presented. The results show that the observed linkage between the PDO and the anomalies of the summer precipitation over East China is well reproduced in our long-term coupled climate model simulations. Furthermore our observation-based analysis and SSTA-forcing experiments results highlight the importance of the SST-forcing in the eastern Pacific Ocean to the variability of the WPSH during the positive PDO phases, which again can modulate the summer precipitation distribution over eastern China. This mechanism is different from previous studies (e.g., Qian et 2013, Zhu et al. 2011), and comparisons of the presented results to these studies are also discussed in this paper.

The rest of the paper is organized as follows. In Sect. 2 we describe the observational data, the model data, and statistical methods used in this study. The results obtained from analyzing the observations and the climate model outputs are presented in Sect. 3 and further discussed in Sect. 4. Finally, the paper is concluded with a summary and final remarks in Sect. 5. 


\section{Data and model simulations}

\subsection{Observations and reanalysis data}

In this study, three independent observed/reanalysis precipitation data sets were analyzed. One is the observed station data obtained from 740 stations collected by the China Meteorological Administration, covering the period from 1957 to 1995 . The two last precipitation data sets are the Climate Research Unit (CRU) precipitation dataset (Mitchell and Jones 2005) and the GPCC full Data Reanalysis Version 6.0 (Schneider et al. 2011), which cover the period from 1900 to 1998 and 1901 to 2010 , respectively. The SST and the surface temperature data sets are from the extended reconstructed version 3 (ERSST V3, Smith et al. 2008) and the NOAA Merged Land and Ocean Surface Temperature (MLOST V3.5.2, Smith et al. 2008). The surface winds and vertical velocities from 1900 to 1999 are obtained from the twentieth century reanalysis data (provided by the NOAA/OAR/ESRL PSD, Boulder, Colorado, USA, from their web site at http://www.esrl. noaa.gov/psd/) and Hadley Centre Sea Level Pressure (SLP) dataset (HadSLP2, Allan and Ansell 2006) were used to investigate circulation changes. Moreover the surface turbulent heat flux (latent + sensible) data used in this study are from the International Comprehensive OceanAtmosphere Dataset (ICOADS).

The statistical methods used in this paper include empirical orthogonal function (EOF) analysis for calculating the PDO pattern, and composite and regression analyses to study teleconnections. All data were detrended prior to computation of the composite and regression maps. A standard Student $t$ test was also used to evaluate the significance of the composite and regression results.

\subsection{The WPSH index}

In the observation-based analysis, the variability of the summer WPSH strength for the 1900-1999 period was analyzed using the standard WPSH strength index $(\mathrm{Mu}$ et al. 2001). It is defined as the accumulated value of the $500 \mathrm{hPa}$ geopotential height (GPH) after subtracting 587 geopotential dynamical meters $(\mathrm{gdm})$ in each grid point in the region of $110^{\circ} \mathrm{E}-180^{\circ} \mathrm{E}$. This is the same definition that is regularly used in operational climate prediction by the Chinese National Climate Center. The data used to calculate the WPSH strength index are the reconstructed northern hemisphere $500 \mathrm{hPa}$ GPH dataset back to the late nineteenth century (Gong and Wang 2000; Gong et al. 2007), which have been proved more reliable for East Asia compared to other reanalysis data (Mu et al. 2001; Gong et al. 2007).
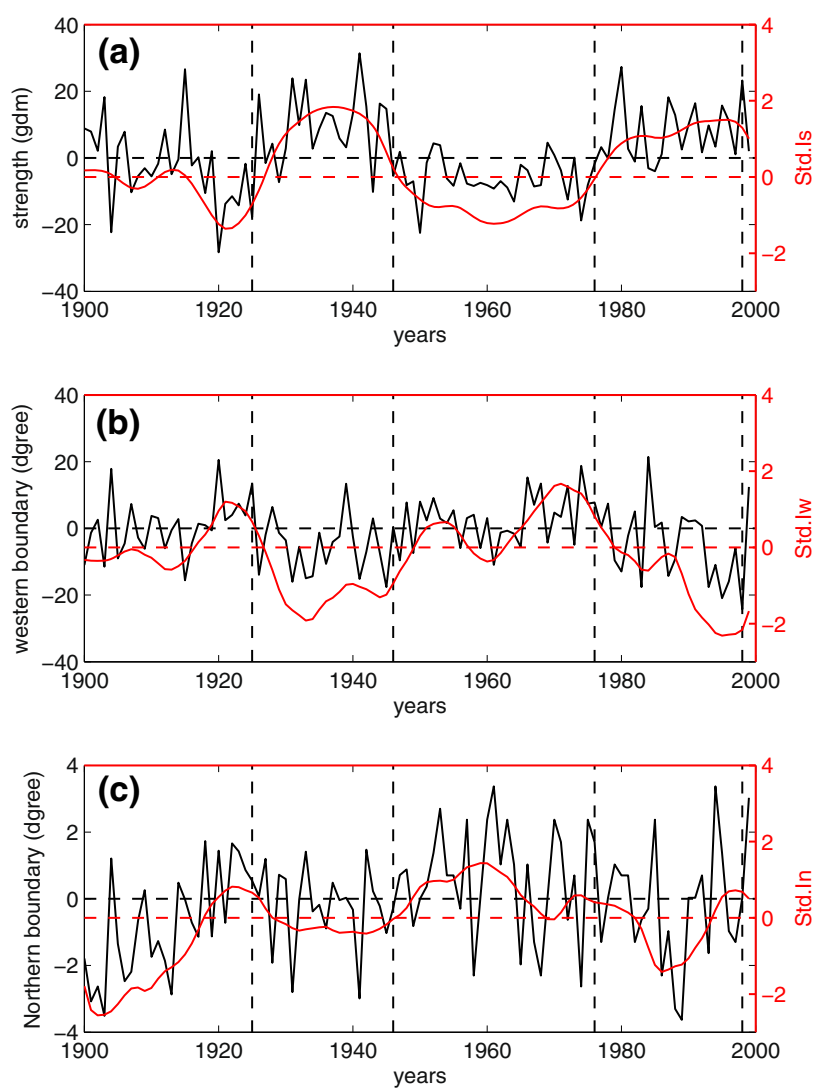

Fig. 1 The annual a strength, b western and c northern boundary anomalies of the WPSH in observations (black curve scaled by the left axes in each panel). Their standard decadal strength index (Is), western boundary index (Iw) and northern boundary index (In) are defined by the standard 9-year running mean, and shown by the red curve in the right axe in each panel

Based on this definition of the WPSH strengthen index, the variability strength of the WPSH is related to changes in its position. This position is normally described by indices of the western and northern boundaries of the WPSH, which are defined as the anomalies in the longitude of the western boundary and the latitude of northern boundary of the $587 \mathrm{gdm}$ contour line in the region of $110^{\circ} \mathrm{E}-150^{\circ} \mathrm{E}$ at $500 \mathrm{hPa}$. The negative values of western and northern boundary indices indicate a southward and a westward shift of the WPSH, respectively, as indicated by Fig. 1. In this study, a 9-year running mean has been applied on all time series in order to focus on the decadal variability. It is found that for periods with a strengthened WPSH (e.g., 1925-1945 and 1976-1990s; Fig. 1a) the mean western boundary of the WPSH extends westward about 18 degree and 20 degree for the early and late periods, respectively (Fig. 1b), and mean northern boundary of the WPSH extends southward about $1^{\circ}$ and $1.5^{\circ}$, respectively (Fig. 1c). Thus, in this study a "stronger" WPSH is concurrent with a south-westward extension of the WPSH, consistent with $\mathrm{Hu}$ (1997) and He and Gong 

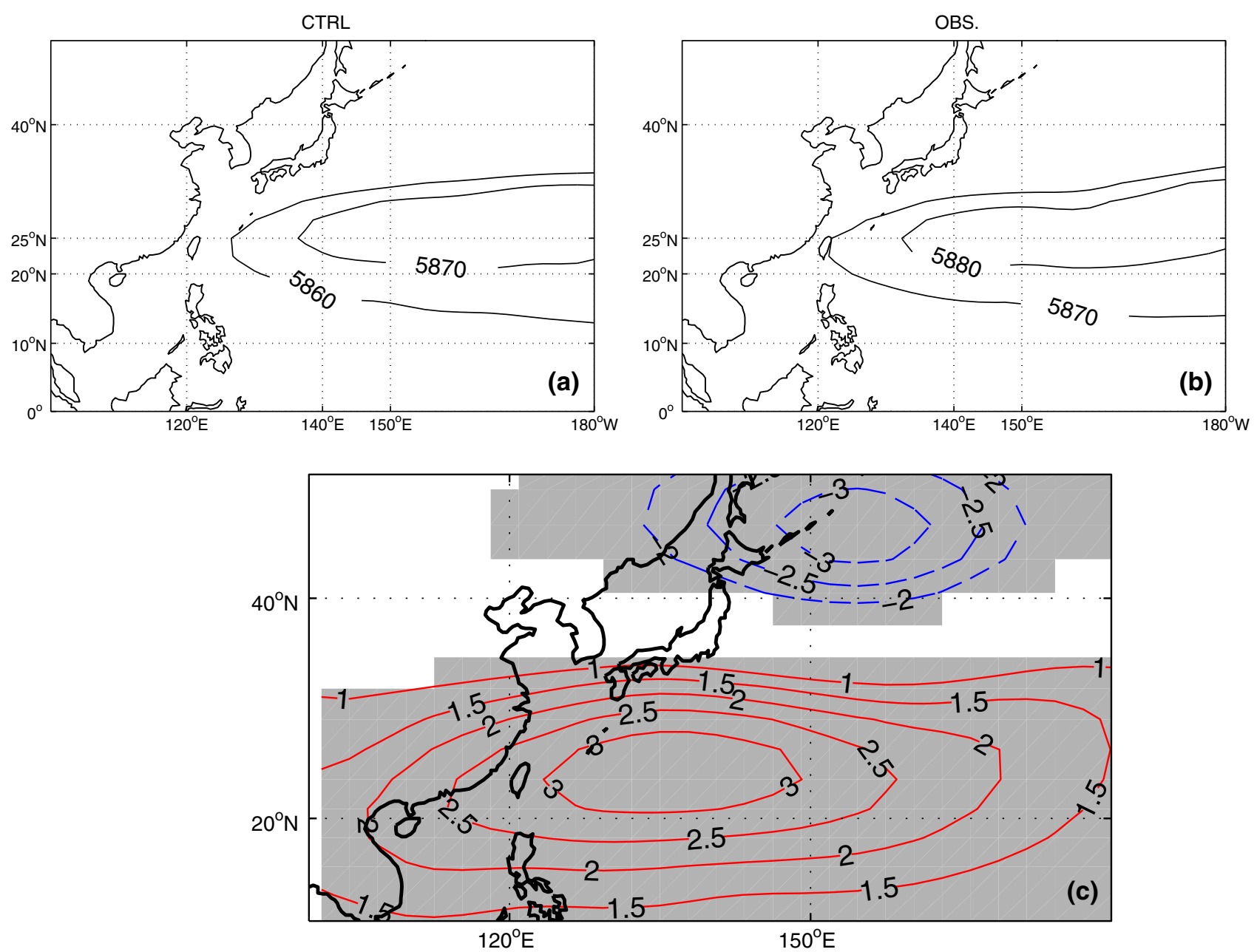

Fig. 2 The mean position of the mean 588 and 587 contour lines $(g d m)$ at $500 \mathrm{hPa}$ in a CTRL and b observations. $\mathbf{c}$ Regression map of the summer $500 \mathrm{hPa}$ geographic heights against the WPSH index in the CTRL. The regressions with confidence levels exceeding $90 \%$ are shaded

(2002). We used the decadal WPSH strength index (red curve Fig. 1a) as the WPSH index in our observationsbased studies.

There are also alternative and somewhat more simplistic ways to define the WPSH index. For examples, Gong and Ho (2002), He and Gong (2002) used the area averaged $500 \mathrm{hPa}$ GPH over the region $125^{\circ} \mathrm{E}-140^{\circ} \mathrm{E}$ and $20^{\circ} \mathrm{N}-$ $25^{\circ} \mathrm{N}$ to measure the WPSH variability and its correlation with the shift of the summer rainfall over the Yangtze River valley in the late 1970s. They pointed out that this particular definition of the WPSH index is sensitivity to changes both in the intensity and extent of the WPSH, and therefore can measure changes both in the position and intensity of the WPSH. In this study, the simulated $500 \mathrm{hPa}$ GPH in our 600-year control run of the BCM are systematically lower than in the observations (Fig. 2a, b). It is therefore clearly inappropriate to use the same approaches as in the observation-based studies to define the WPSH index. From Fig. 2a, the mean position of the WPSH ridge is found in the region $120^{\circ} \mathrm{E}-140^{\circ} \mathrm{E}$ and $20^{\circ} \mathrm{N}-25^{\circ} \mathrm{N}$ in the model. We thus followed He and Gong (2002) and defined the WPSH index as the standard mean $500 \mathrm{hPa}$ GPH anomalies in JJA averaged over the region within $125^{\circ} \mathrm{E}-$ $140^{\circ} \mathrm{E}, 20^{\circ} \mathrm{N}-25^{\circ} \mathrm{N}$. In the model significant positive correlations between this index and the $500 \mathrm{hPa}$ GPH field can be seen over the western Pacific Ocean, with a western extension to the southeastern parts of China and a center of action over the Philippines Sea (Fig. 2c).

\subsection{Model description}

The climate model used in this study is an updated version of the BCM (Otterå et al. 2009), a global, coupled atmosphere-ocean-sea-ice general circulation model (GCM). The atmosphere component is the spectral atmospheric GCM ARPEGE (Déqué et al. 1994). In this study, ARPEGE is run with a truncation at wave number 63 (TL63), and a time step of 1800s. All the physics and the treatment 
of model nonlinear terms require spectral transforms to a Gaussian grid. The physical parametrization is divided into several explicit schemes, each calculating the flux of mass, energy and/or momentum due to a specific physical process (Furevik et al. 2003).

The ocean component is MICOM (Bleck and Smith 1990; Bleck et al. 1992), a global isopycnic coordinate ocean GCM. In the version of MICOM used in this study, several important aspects deviate from the original model and the one used in the original version of the BCM (Furevik et al. 2003). The sea-ice model is GELATO, a dynamic-thermodynamic sea-ice model that includes multiple ice categories (Salas Mélia 2002). The OASIS (version 2) coupler (Terray et al. 1995) has been used to couple the atmosphere and ocean models. Full detailed descriptions about BCM2 can be found in (Otterå et al. 2009).

Additionally, two pairs of SST sensitivity experiments were performed based on the ARPEGE and the Community Atmosphere Model (CAM 3.0) to investigate responses of the WPSH to SSTA in the eastern tropical Pacific. The CAM 3.0 used in this study is the fifth generation of the atmospheric GCM developed at NCAR for the weather and climate research communities. CAM also serves as the atmospheric component of the Community Climate System Model. The details of the governing equations, physical parameterizations, and numerical algorithm in the CAM 3.0 can be found in the technical report by Collins et al. (2004), and is therefore not described further here.

\subsection{The BCM control simulation}

In order to study the linkage between the natural decadal variability of the summer precipitation pattern over East China and PDO, and to test the mechanism put forward based on observations analyses, a pre-industrial control (CTRL) simulation with BCM was also analyzed. The CTRL is a 600-year long simulation, where the well-mixed greenhouse-gas concentrations and the tropospheric sulphate aerosols are fixed at pre-industrial level, and there are no year-to-year variations in the natural external forcings. The model was run without any flux adjustments. A detailed description of the CTRL simulation and an its evaluation against observations can be found in Otterå et al. (2009), so here only a few points are highlighted. The CTRL reproduces the major features of the global climate and is stable for several centuries (Otterå et al. 2009). In particular, the CTRL simulation reproduces the main precipitation patterns including those associated with the midlatitude storm tracks and the continental monsoons. However, there is a general tendency to underestimate the amount of precipitation compared to the observations over the ocean. In terms of simulated SSTs, the main errors are seen in the Southern Ocean compared to the Levitus data
(Levitus and Boyer 1994) and are mainly caused by negative sea-ice biases here.

\section{Results}

\subsection{Linking the PDO and summer precipitation over the East China}

Following Mantua et al. (1997) and Zhang et al. (1996), the PDO pattern is defined as the leading EOF of residual SSTAs between $20^{\circ} \mathrm{N}$ and $65^{\circ} \mathrm{N}$ in the North Pacific Ocean in winter (December-January-February, DJF) for the period 1900-1999. The PDO index is defined as the lowpass filtered ( $\geq 9$ years) principal components (PC1) in order to focus on the decadal-interdecadal variations. The residual SSTAs are created by subtracting the global mean anomaly from each North Pacific Ocean grid point $\left(20^{\circ} \mathrm{N}-65^{\circ} \mathrm{N}\right)$ for all months during the studied period in order to remove any global warming signals (http://jisao.washington.edu/pdo/ PDO.latest). The temporal evolution of the observed PDO index can be divided into three different periods (Fig. 3a): a positive period from 1925 to 1946 (hereafter referred to as P1), a negative period from about 1947 to 1976 (hereafter referred to as N1), and a positive period from 1977 to the late 1990s (hereafter referred to as P2). Figure 4a shows the spatial pattern of the observed winter SSTA and SLP anomalies (SLPAs) during positive PDO phases. The SSTs tend to be below normal in the central North Pacific Ocean, and with a horseshoe-like warming in the eastern subtropical Pacific Ocean along the west coast of the North American continent. At the same time, a strengthened Aleutian Low (decreased SLP) is dominating over the central-eastern subtropical Pacific with a southeastern extension to around $20^{\circ} \mathrm{N}$ over the eastern Pacific Ocean.

The low-pass filtered PC1 of simulated residual SSTAs between $20^{\circ} \mathrm{N}$ and $65^{\circ} \mathrm{N}$ in the North Pacific also exhibits decadal variations with two general periodicities of 10-30 and 50-70 years (Fig. 3b), and with no apparent trend during the whole 600-year integration period. For the simulated winter SSTA pattern during phases of positive PC1, a cooling is evident in the central subtropical North Pacific Ocean, surrounded by a horseshoe-like warming in the eastern subtropical Pacific Ocean. At the same time, a decreased SLP in the central North Pacific can also been seen (Fig. 4b). These features resemble the observations quite well, indicating that the model qualitatively can capture the pattern of the observed PDO. The exact causes for the PDO and the mechanisms for its variations are still uncertain. However, a detailed examination of these issues is beyond the scope of this study. Here, on the other hand, the influences of the PDO on the summer precipitation over East China will be addressed in more detail. 
Fig. 3 The PDO index calculated by a the ERSST V3 dataset and $\mathbf{b}$ the 600-years CTRL simulation
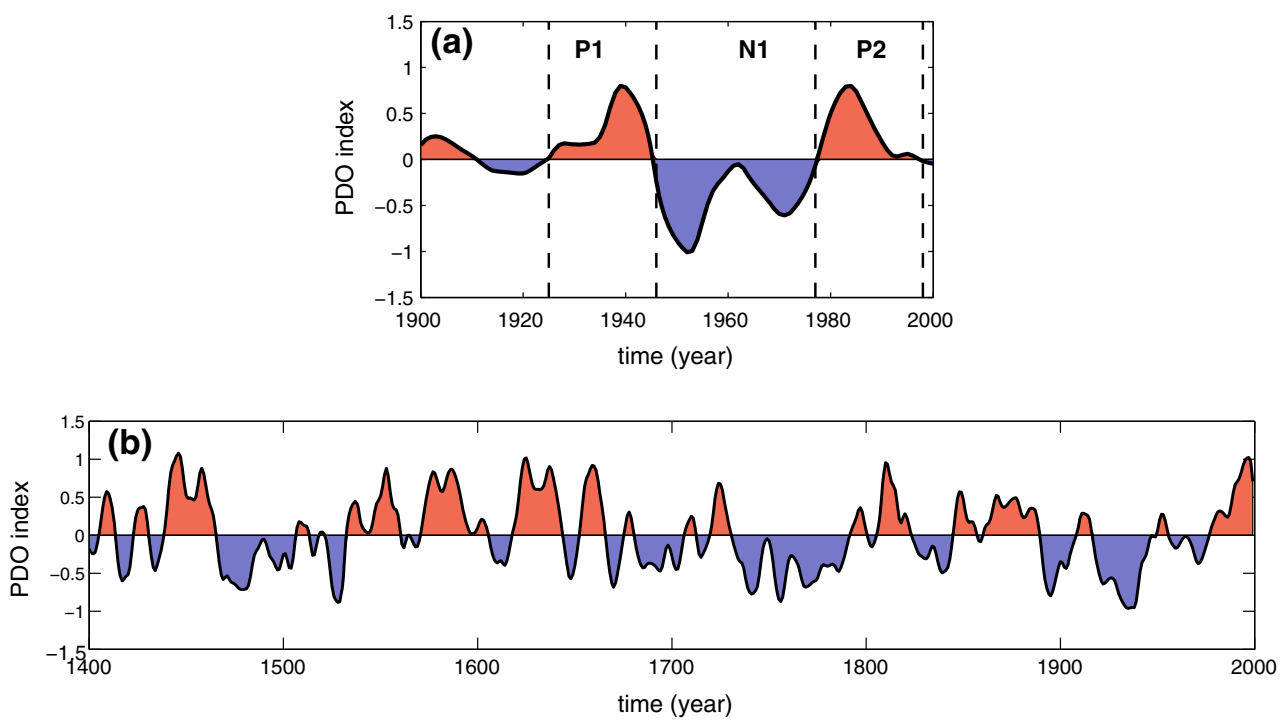

Observations

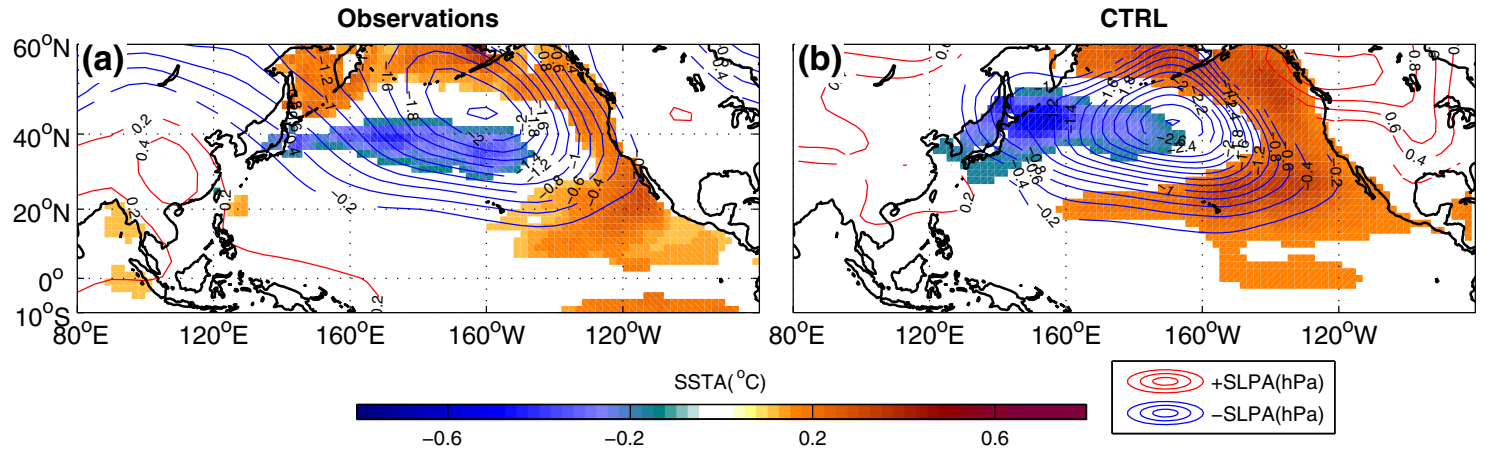

Fig. 4 The winter SSTA (color shaded) and SLPA (contours) pattern during positive PDO phases in a observations over 1900-1999 and b CTRL. Only anomalies with confidence levels exceeding $90 \%$ are plotted

As a first step we diagnose the observed differences in summer precipitation between positive and negative PDO phases from the observations (Fig. 5). The characteristic YFND pattern can be seen when comparing the differences between $\mathrm{P} 2$ and $\mathrm{N} 1$. Over the northern $\left(112^{\circ} \mathrm{E}-122^{\circ} \mathrm{E}\right.$ and $34^{\circ} \mathrm{N}-40^{\circ} \mathrm{N}$ ) and southern parts of China reduced precipitation is found, while more precipitation are encountered in vicinity of the $\mathrm{YRV}$ region $\left(105^{\circ} \mathrm{E}-122^{\circ} \mathrm{E}\right.$ and $\left.27^{\circ} \mathrm{N}-33^{\circ} \mathrm{N}\right)$ in all of the three independent observed/reconstructed datasets. The differences between $\mathrm{P} 1$ and $\mathrm{N} 1$ also show similar characteristics as those found between P2 and N1, with more summer precipitation over the YRV region, but less over North China. A distinct difference is found in the southernmost parts of China, where the P1 minus N1 composite shows more precipitation while the $\mathrm{P} 2$ minus N1 composite shows less. The results nevertheless points to a modulation of the PDO to the south-north shift of the summer precipitation over eastern China during the last century. In order to further explore this potential linkage, composites of summer precipitation were made for the period 1900-1999 based on differences between positive and negative PDO phases (Fig. 6a, b). The results also show a characteristic YFND pattern. Such an YFND-like pattern was also obtained by examining the composites between positive and negative PDO periods based on CTRL (Fig. 6c).

Figure 7 shows the surface monsoon circulation associated with the precipitation anomalies during positive PDO phases. In the observations (over 1950-1999), the $850 \mathrm{hPa}$ winds show anomalous northerlies and a substantial higher SLP during the positive PDO phases over the East Asian continent (Fig. 7a). For the model simulation, there is also a higher SLP over the East Asian continent, but with a more eastward extension than in the observations (Fig. 7b). Also, anomalous $850 \mathrm{hPa}$ northerlies over land can be seen. Relatively large discrepancies are found between the model and the observations over the Japanese Sea. Here, the model simulates anomalous northwesterly winds, while in the observations anomalous northeasterly winds are found. However, overall the anomalous surface monsoon circulation in the model shows a similar surface circulation pattern over the East China continent to the observations, with anomalous northerlies and 

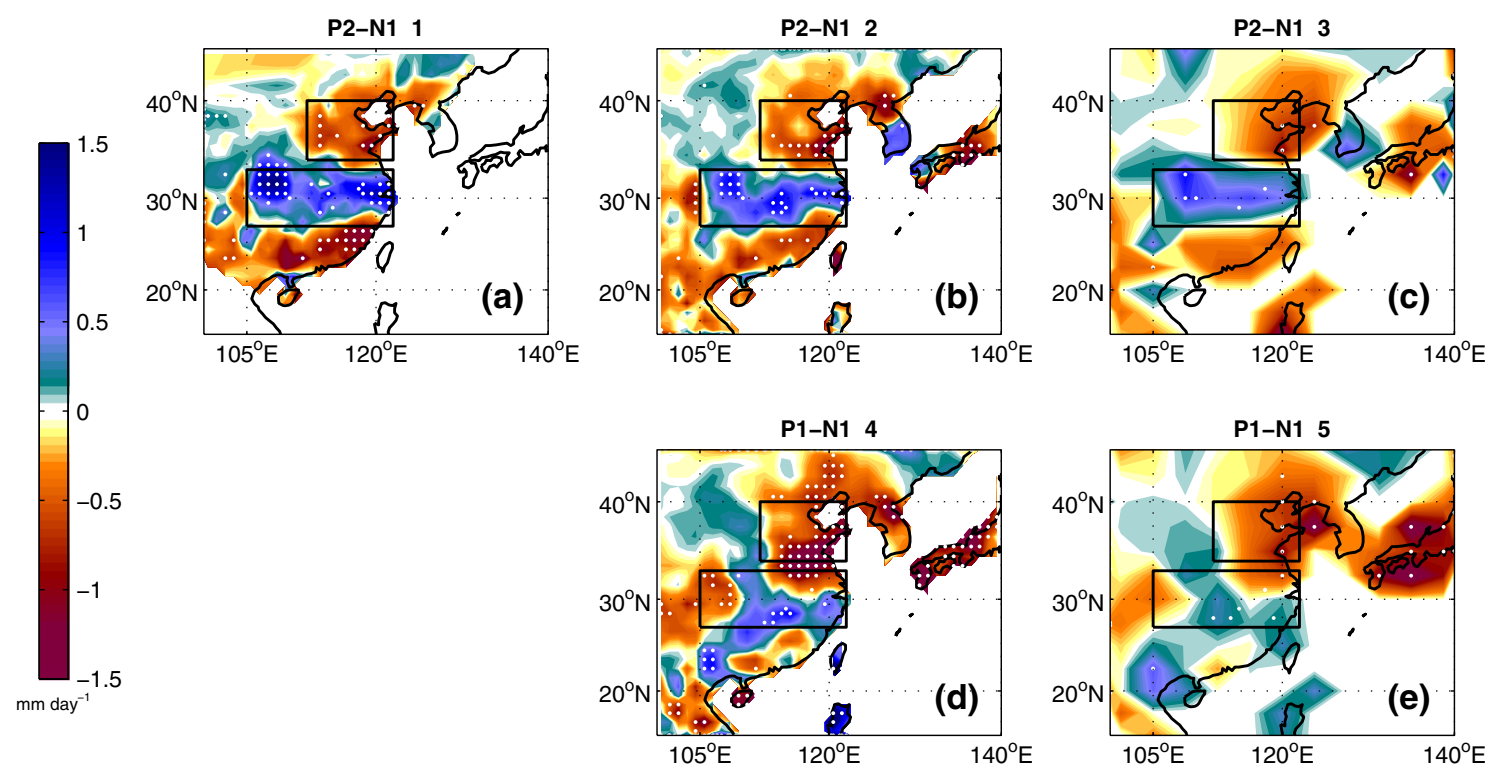

Fig. 5 Differences of summer precipitation over East China between P2 and N1 in the a station data, b GPCC and $\mathbf{c}$ CRU dataset; and differences between P1 and N1 in the $\mathbf{d}$ GPCC and e CRU dataset. The two black rectangles denote North China (upper $112^{\circ}-122^{\circ} \mathrm{E}$ and $34^{\circ}-40^{\circ} \mathrm{N}$ ) and $\mathrm{YRV}$ region (lower $105^{\circ}-122^{\circ} \mathrm{E}$ and $27^{\circ}-33^{\circ} \mathrm{N}$ ). The differences with confidence levels exceeding $90 \%$ are denoted with white dots

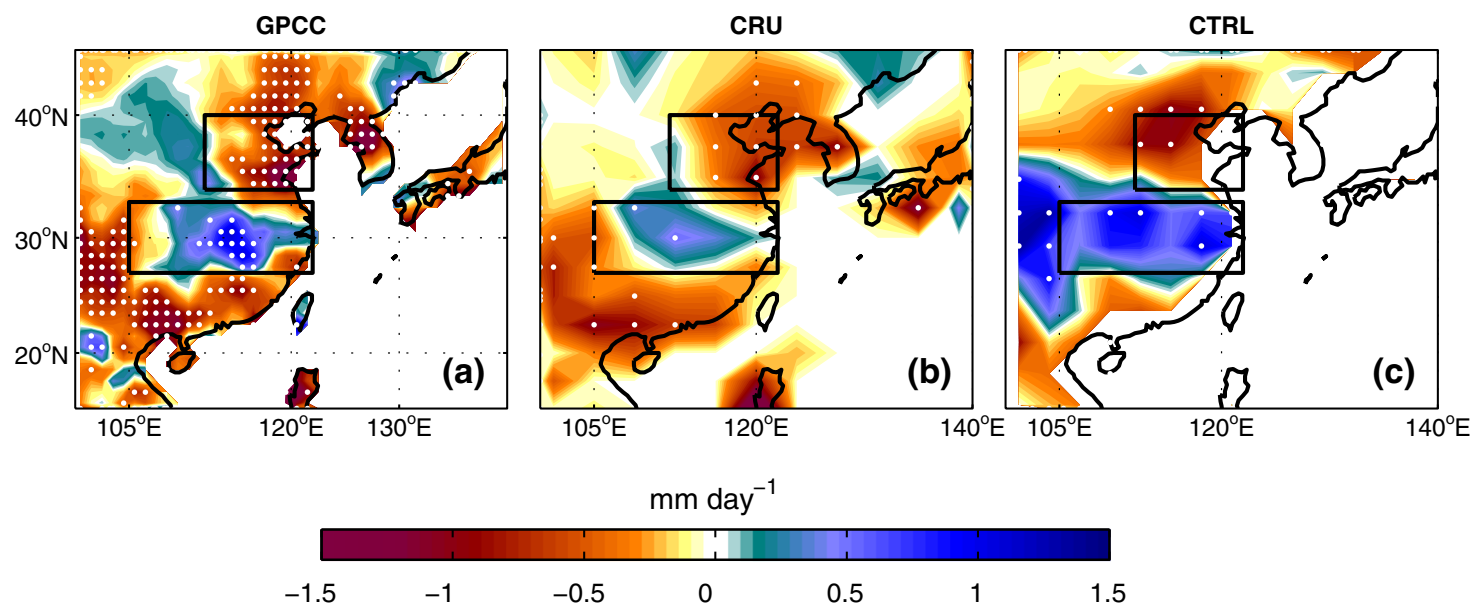

Fig. 6 Composites of summer precipitation over East China based on differences between positive $(>0)$ and negative $(<0)$ phases of the PDO in a GPCC (1901-1999), b CRU dataset (1900-1998) and

a higher SLP. Such a circulation pattern indicates a weakened northward water vapor transport into North China, corresponding to less precipitation over North China during the positive PDO phases, and for the earlier positive PDO phase (P1, 1925-1946), reduced northward water vapor transport into North China can also been found in the observations (see Fig. 21).

The potential correlation between the "YFND" pattern and the PDO based observed data has been reported in a previous study (Yu 2013). In this study, these analyses are extended to a long-term CTRL run of the BCM, thus c CTRL simulations. The differences with confidence levels exceeding $90 \%$ are denoted with white dots

providing a more robust modeled framework for examining the potential mechanisms.

\subsection{The mechanism}

Previous studies (e.g., Hu 1997; Gong and Ho 2002) showed that the strengthening and the southwest-ward extension of the WPSH is primarily responsible for an increased precipitation over the YRV region, also some studies found an anti-correlation between the PDO and precipitation over North China (e.g., Ma 2007; Zhu et al. 


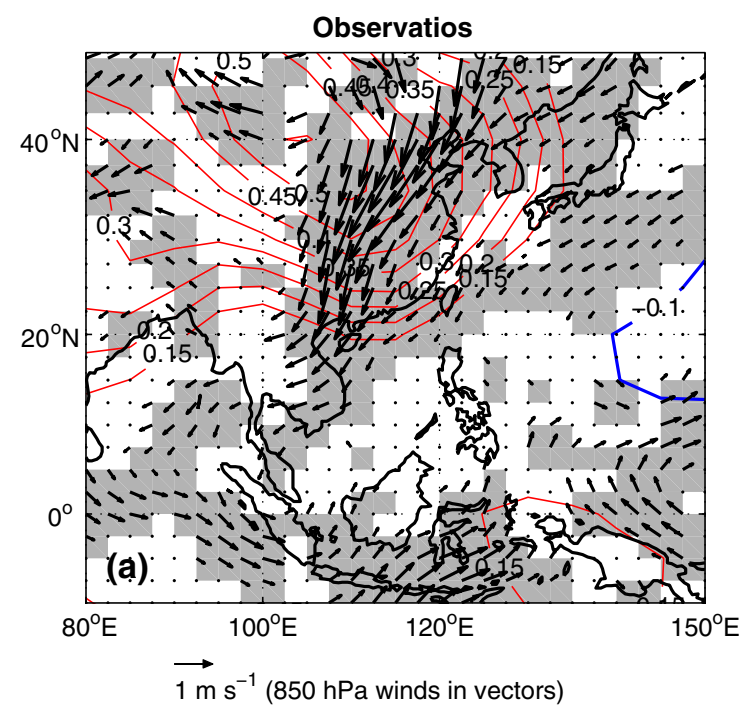

Fig. 7 Composite of summer (JJA) $850 \mathrm{hPa}$ winds (vectors $\mathrm{ms}^{-1}$ ) and SLP (contour lines $h \mathrm{~Pa}$ ) based on differences between positive $(>0)$ and negative $(<0)$ phases of the PDO in a observations and
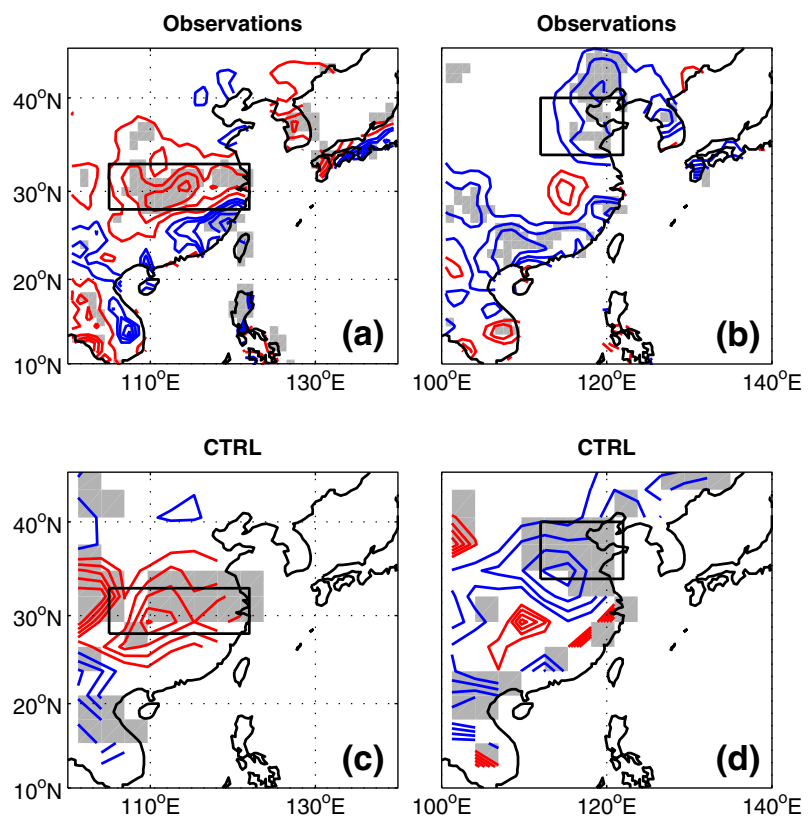

Fig. 8 Regression map of the summer (JJA) precipitation over East Asia against a WPSH and b PDO index in the observations (the precipitation data is from GPCC). The unit of the contour lines is $\mathrm{mm}$ day $^{-1}$ per gpm in a and $\mathrm{mm}$ day $^{-1}$ per standardized PDO index in $\mathbf{b}$. The values of contour lines are $-0.5,-0.3,-0.2,-0.1$ (in blue contours) and 0.1, 0.3, 0.5, 0.7 (in red contours). $\mathbf{c}$ and $\mathbf{d}$ Is same as a and $\mathbf{b}$ but for CTRL. The regressions with confidence levels exceeding $90 \%$ are shaded

2011). The relationships between the "YRV floods" and stronger WPSH, and between the "Northern drought" and positive PDO are clearly demonstrated by regressing the summer precipitation over East China against decadal

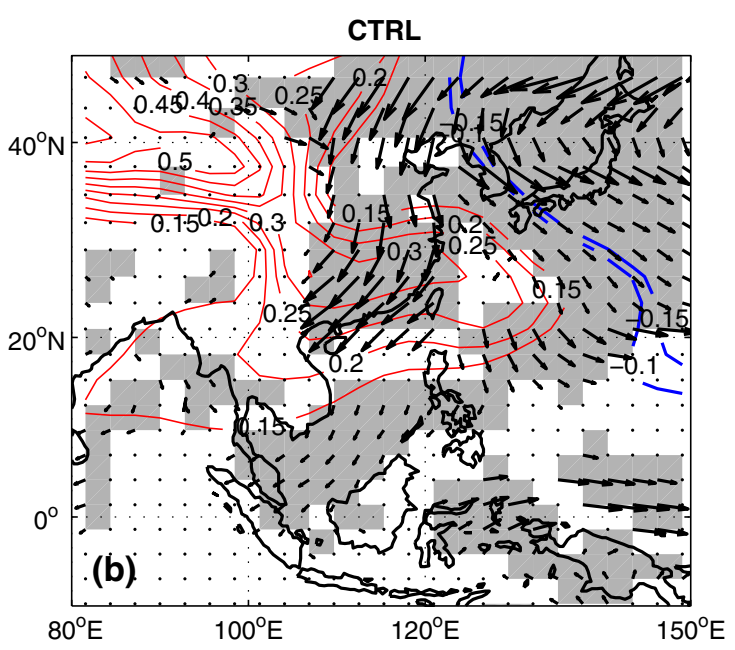

b CTRL. Only the differences with confidences level exceeding $90 \%$ are plotted, and differences of winds are shaded

WPSH and PDO indices in the observations and in CTRL (Fig. 8): we can note that increased precipitation over the YRV region is associated with positive values of the WPSH index, and that reduced precipitation over North China is related to positive values of the PDO index. In Figs. 5 and 6, the observed "YRV floods" and "Northern drought" are concurrently evident during positive PDO phases. It therefore seems reasonable to expect that a stronger WPSH is needed to produce an YFND pattern over East China during the positive PDO phases. In the observations, the WPSH is found to intensify during the P1 and P2 periods, respectively (Fig. 9a). For the CTRL simulation, the WPSH index is found to co-vary closely with the PDO index, with a correlation at zero lag of 0.67 at $95 \%$ confidence (Fig. 9b).

In summer, the observed SSTAs are positive in the eastern tropical Pacific (ETP, here defined by region over $5^{\circ} \mathrm{N}-20^{\circ} \mathrm{N}$ and $160^{\circ} \mathrm{W}-120^{\circ} \mathrm{W}$ ) during positive PDO phases (Fig. 9a). For the equatorial region $\left(0^{\circ} \mathrm{N}-5^{\circ} \mathrm{N}\right)$, some positive SSTAs can be found during $\mathrm{N} 1$, while negative SSTAs are found in P1 for this region. This indicates that the positive SSTAs in the eastern tropical Pacific in summer are probably related to the positive PDO and are mainly located between $5^{\circ} \mathrm{N}$ and $20^{\circ} \mathrm{N}$.

Previous studies have shown evidence of positive SSTanomalies in the tropical Indo-western Pacific (IWP) and Pacific equatorial region when taking the difference between positive (P1 and P2) and negative (N1) PDO phases (e.g., Fig. 7e in Qian and Zhou 2013). Similar results are found in composite analysis (Fig. 10a) based on the same composite method. However, for the earlier positive PDO phases (P1, Fig. 10c), significant positive 

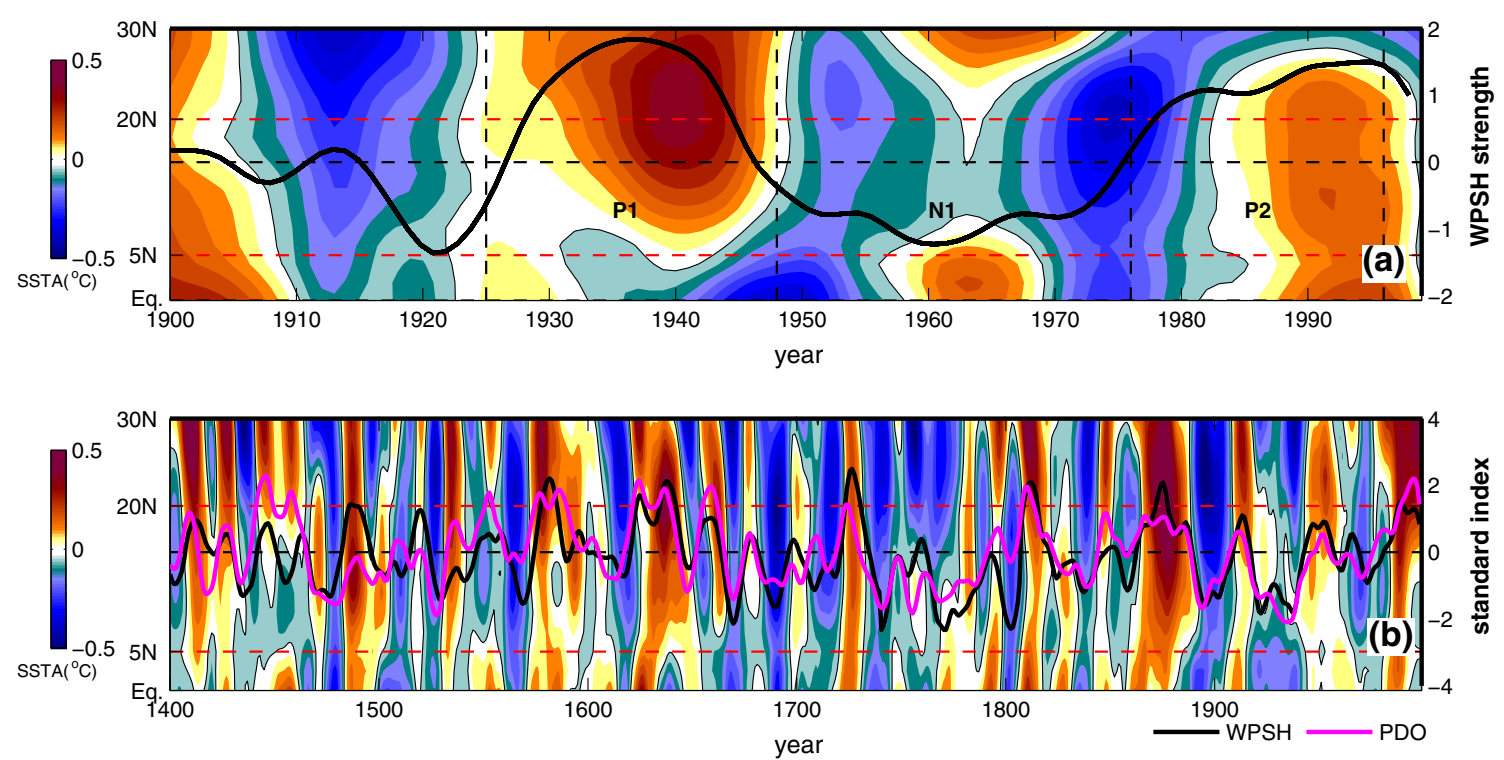

Fig. 9 Decadal variability of the summer (JJA) SSTAs (color shaded) in the eastern subtropical-tropical Pacific (averaged over $160^{\circ} \mathrm{W}-120^{\circ} \mathrm{W}$ at each latitude) and the standard WPSH index (bold black curve) in a observations and b CTRL. Additionally the PDO

SSTAs in the tropical Indian Ocean $\left(0^{\circ} \mathrm{S}-20^{\circ} \mathrm{S}\right)$ were limited and even significant negative SSTAs in the tropical Western Pacific can be seen. Meanwhile, negative SSTAs were located in the central equatorial Part. A Comparison of Fig. 10a with Fig. 10c and b shows clearly that in the Fig. 10a the composite significant positive SSTAs found in the IWP and in the equatorial regions mainly represent the strong warm signals in these ocean regions only in P2 (after 1970s, Fig. 10b), but not in the P1 (see Fig. 10c). The comparison also indicates the common significant tropical warming in the North Pacific both in the P1 and P2 were located mainly in the off-equatorial region.

Since the studied period is the whole last century in this paper, we need to obtain a more representative common SSTAs pattern of the positive PDO for the whole last century. In order to accomplish this, we made SSTAs composite where the difference between positive PDO phases and the climatological mean SST (rather than the negative PDO) were taken. The climatology SST is calculated as the mean of 1900-1999. The resulting composite boreal summer SSTAs are shown by Fig. 10d (see Fig. 4a in this paper for the composite boreal winter SSTAs pattern by same way). From Fig. 10d, significant warming is located mainly $5^{\circ} \mathrm{N}-20^{\circ} \mathrm{N}$ in the eastern tropical of the North Pacific, and not far to the equatorial region $\left(0^{\circ} \mathrm{N}-\right.$ $5^{\circ} \mathrm{N}$ ). In the tropical western Pacific on the other hand, no significant warming in the tropical western Pacific can be seen. Meanwhile significant cooling can be found in the central Pacific. According to Fig. 10b, c, the composite SSTAs in Fig. 10d is more representative of the SSTAs in index based on CTRL simulation is also shown by pink curve in b. The dashed red lines in each panel denote the tropical region between $5^{\circ} \mathrm{N}$ and $20^{\circ} \mathrm{N}$. All variables are smoothed by using 9 -year running mean to highlight the decadal variability

the North Pacific under the positive PDO phases during the whole last century.

To study the correlation between the decadal variability of the WPSH and North Pacific basin SSTAs, we calculated the regression of SSTAs against the observed WPSH index in the observations and CTRL. Here the SSTAs are the SST anomalies relative to their climatic mean over 1900-1999. In the observations, significant positive values are located in subtropical Eastern Pacific with a tropical extension to $5^{\circ} \mathrm{N}$, while negative values are found in the subtropical centralwestern Pacific, meanwhile some positive correlations can be seen in the IWP (Fig. 10e). Further comparison between the regression over 1971-1999 and 1900-1970 (Fig. 10g, h) shows clearly that the positive correlations in the IWP and equatorial regions are significant mainly over 1971-1999 (Fig. 10g), but not over 1900-1970 (Fig. 10h), while in the ETP significant positive correlations can be found both in these two period. This similar regression pattern was found in the 600-year CTRL results (Fig. 10f) with significant positive correlations between the strengthening of the WPSH and the positive SSTAs in the ETP.

In summary, the above-mentioned studies indicate that the summer warming in the ETP during the positive PDO phases and the associated intensified WPSH are the key factors for the mechanism involving a modulation of the PDO on the summer precipitation over East China. However, before any firm conclusions can be drawn two questions need to be answered: What are the causes for the summer warming in the ETP during positive PDO phases? And, can such a warming generate a strengthened WPSH? 

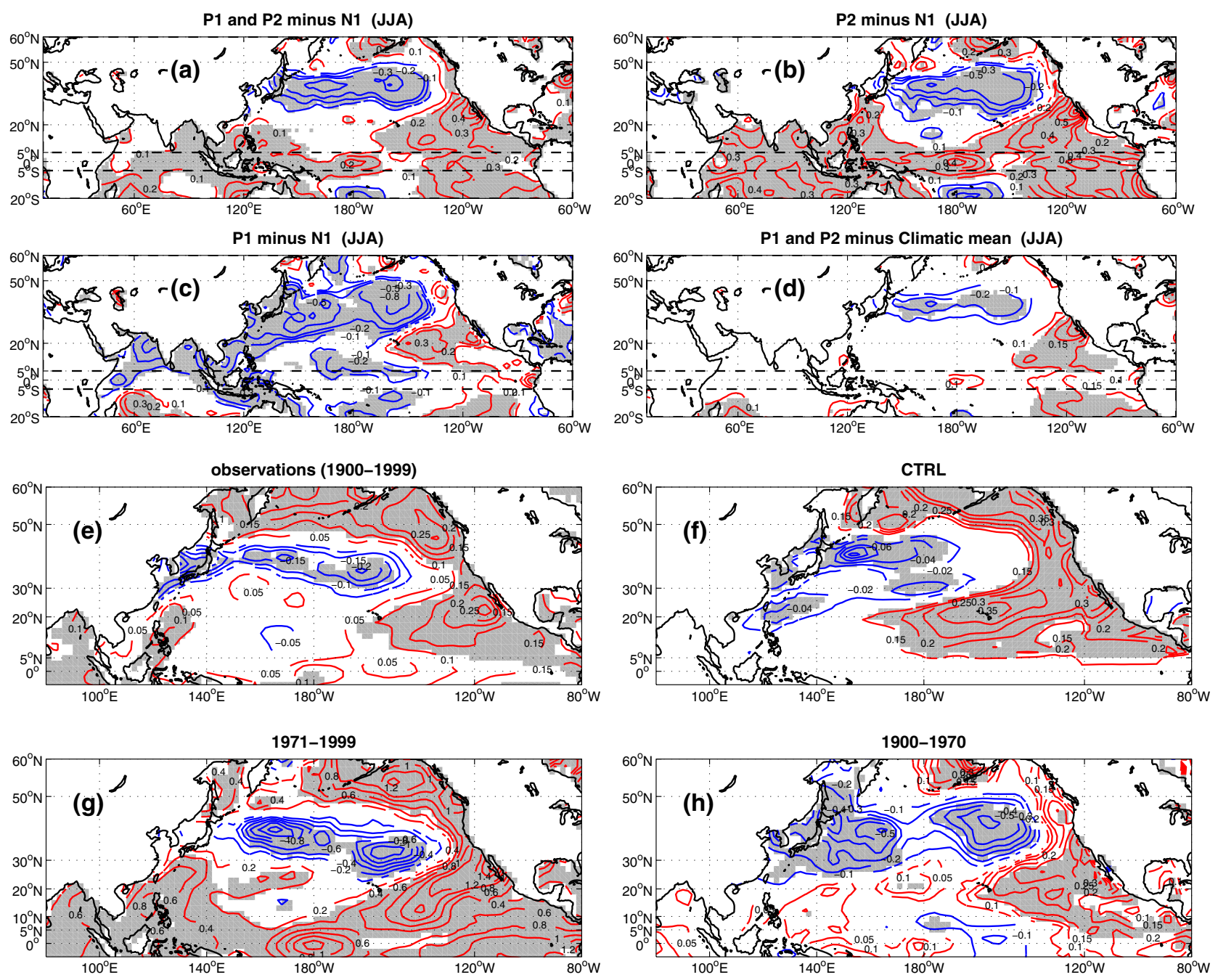

Fig. 10 a The composite SSTA by P1 and P2 minus N1 (1976-1998 and 1925-1945 minus 1946-1975). The SSTA differences b between P2 (1976-1998) and N1 (1946-1975), c between P1 (1925-1945) and N1 (1946-1975), and d the composite SSTA by P1 and P2 minus climatic mean. Regression map of the decadal WPSH strength index

To answer these two questions, we have to turn to numerical models. Thus, we investigated potential mechanisms for the summer warming in the ETP during the positive PDO phases by analyzing and comparing observations and the model output from a pre-industrial control simulation from a coupled atmosphere-ocean general circulation model (the $\mathrm{BCM}$ ). In addition, we performed AGCM experiment with prescribed SST to better determine the contribution of the warming in the ETP to an intensification of the WPSH.

\subsubsection{Assessing the summer warming in the ETP under the positive PDO}

A horseshoe-like warming has been identified in eastern subtropical Pacific along the west coast of North American in winter of positive PDO phases (Fig. 4). At the same time

against the North pacific basin SSTAs in summer (JJA) in e observations over 1900-1999, f CTRL, $\mathbf{g}$ observations over 1900-1970 and h over 1971-1999. The areas of confidence level exceeding $90 \%$ are denoted shaded

a warming in the ETP has been found during positive PDO phases in summer (Figs. 9, 10). Earlier studies (e.g., Vimont et al. 2001) have suggested that mid-latitude atmospheric variability in winter can generate subtropical SSTAs, which are then transmitted to the tropics in the following summer by a seasonal coupling process involving the winter mid-latitude atmospheric anomalies and the tropical summer wind stress anomalies. Wu et al. (2007) also suggested that positive subtropical and extra-tropical SSTAs may propagate to the tropics through a coupled wind-evaporative-SST (WES) feedback, which gives rise to a delayed adjustment of the meridional overturning circulation in the upper ocean that can sustain the tropical SST changes on decadal time scales. Based on these studies, we speculate the warming in the ETP in summer originates from the eastern subtropical and extra-tropical 
Pacific during positive PDO phases. The coupled WES process is illustrated for the observations and the model by time-latitude plots (Fig. 11a, b) of SSTAs, surface winds and turbulent heat fluxes (latent + sensible) averaged over each latitudinal band between $160^{\circ} \mathrm{W}$ and $140^{\circ} \mathrm{W}$ during positive PDO phases. In the observations (Fig. 11a), anomalous southwesterly winds can be seen in winter (JanFeb) over the eastern subtropics (north of $15^{\circ} \mathrm{N}$ ). Associated with the anomalous south-westerly winds are the reduced heat loss (positive value indicates the downward heat flux) from the sea surface to the atmosphere, which result in a warming center around $20^{\circ} \mathrm{N}$. From winter to spring and into the summer season (March-August), the warming propagates to the tropics together with a southward extension of the southern westerly winds and a positive heat flux. Finally, in summer (JJA) a positive heat flux center can be found between the $5^{\circ} \mathrm{N}-20^{\circ} \mathrm{N}$, which corresponds to the south-westerly winds here. At the same time positive SSTAs are centered at the same location. The observed propagation of positive SSTAs from the subtropics and extratropics to the tropics through the WES processes is reproduced in the CTRL simulation (Fig. 11b). A similar mechanism has also been identified in wind stress model sensitivity experiments by $\mathrm{Wu}$ et al. (2007). They used the observed anomalous monthly winds to drive the ocean component of the coupled system over the North Pacific. Their results offered clear model evidences for a propagation of warm SSTAs from the winter subtropics to summer tropics through the WES process. As suggested by Wu et al. (2007), given the existence of decadal SSTAs in the subtropics (such as the PDO) it is conceivable that the fast WES process can continuously bring eastern subtropical warming to the tropics in each year to sustain a decadal warming of the tropical region. However, it should be pointed out that the WES process is a fast-coupled process that works reasonable at annual time scales. In order to further study the possible mechanism for the decadal warming in the ETP during the positive PDO, the slow oceanic process of the meridional circulation in the eastern upper Pacific Ocean must also be examined. Through this circulation the cool subtropical water subduct into the pycnocline (where the water density increases rapidly with depth), and then move to the surface in the tropics within about a decade, maintaining the relative cold SSTs in the ETP. The coupled model simulation provide us with easilyobtained vertical temperature changes and volume transports in the upper Pacific Ocean that can be used to test to what extent the slow changes in this circulation can act as an oceanic tunnel during the positive PDO phases.

The temporal changes of the meridional-vertical ocean temperature in the eastern Pacific Ocean are shown in Fig. 12. In the beginning of a positive PDO phase (the first 2 years), a concurrent surface warming in the tropics $\left(5^{\circ} \mathrm{N}-\right.$ $20^{\circ} \mathrm{N}$ ) and in the subtropics (north of $20^{\circ} \mathrm{N}$ ) can be found. During this period, no clear connection can be found between the subtropics and the tropics, and the warming in the tropics is generated predominately by the fast WES process during the first few years of the PDO phases when the warming in eastern subtropical ocean first appears. However, in the following years, a clear connection can be found between subtropics and tropics where the warming penetrates down from the subtropics to the tropics (Fig. 12b). In particular during years 3-4, a significant warming appears in the tropics in the subsurface layers, which is then extended into the surface after about 4 years (Fig. 12c). This further sustains the warming in the tropical surface on decadal time scales (Fig. 12d).

A weakening in the merdional overturning circulation (Fig. 13) in the upper ocean layers during positive PDO phases in model is crucial for explaining the sustained warming on decadal time scales. The averaged meridional streamfunction in the upper Pacific Ocean shows a clockwise circulation in the northern hemisphere (Fig. 13a), by which the relative cold subtropical water masses are transported into the tropical surface in about one decade. During the first few years of the positive PDO phases, the meridional overturning circulation shows a reduced mass transport, which is mostly located in the tropical cell in the upper $200 \mathrm{~m}$ (Fig. 13b). This can largely be seen as a response to the anomalous southwesterly surface winds associated with the fast WES process. The weakening of the circulation in the later stage (years 5-15) extends more broadly merdionally compared to the earlier stage, suggesting a delayed adjustment of the subtropical cell. This will again result in reduced transports of the relative cool subtropical water masses into the tropical surface through the subtropical-tropical ocean cell, which is ultimately the reason for the persistent inter-decadal warming in the tropics (Fig. 12c, d).

The above mentioned studies suggest that the slowdown of the meridional circulation in the upper eastern Pacific Ocean is the main cause for the decadal surface warming in the ETP. Meanwhile, the results also suggest that during the early years of the PDO phases, when the warming in eastern subtropical appears, the fast WES process can cause concurrent warming in the tropics. As suggested by Wu et al. (2007), the repeating annual WES process during positive PDO years results in an accumulation of the anomalous warm surface waters and southwesterly winds. This ultimately conditions the surface for a slow-down of the meridional circulation in the eastern Pacific upper ocean layers, thus providing the necessary positive feedback to sustain the surface warming in the ETP region.

Also, from Fig. 13c, during years 4-15 of the positive PDO, the weakening of the meridional circulation has 
Fig. 11 Time-latitude plot of SSTAs (contours ${ }^{\circ} \mathrm{C}$ ), anomalous surface turbulent heat flux (latent + sensible $\mathrm{W}$ $\mathrm{m}^{-2}$, color shaded) and surface winds ( $\mathrm{m} \mathrm{s}^{-1}$ vectors) during positive PDO phases in a observations and b CTRL. All variables are averaged over $\left(160^{\circ} \mathrm{W}-120^{\circ} \mathrm{W}\right)$
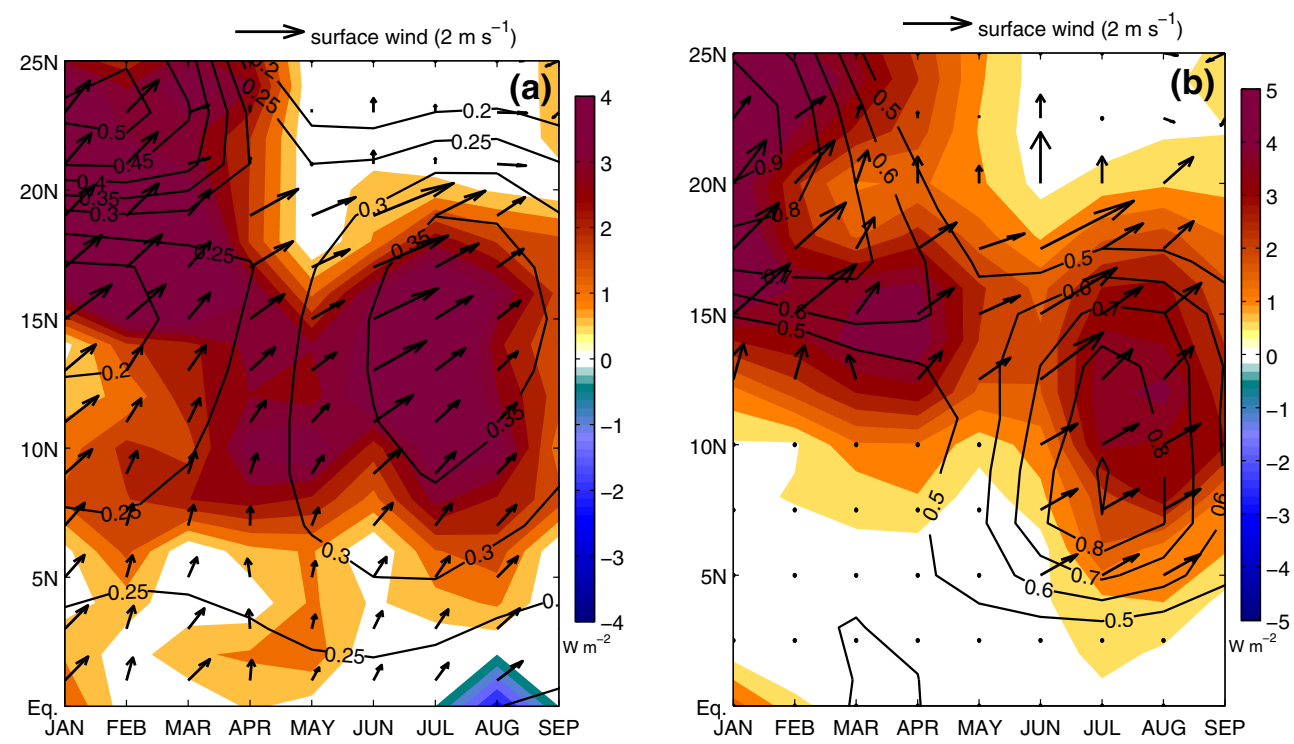
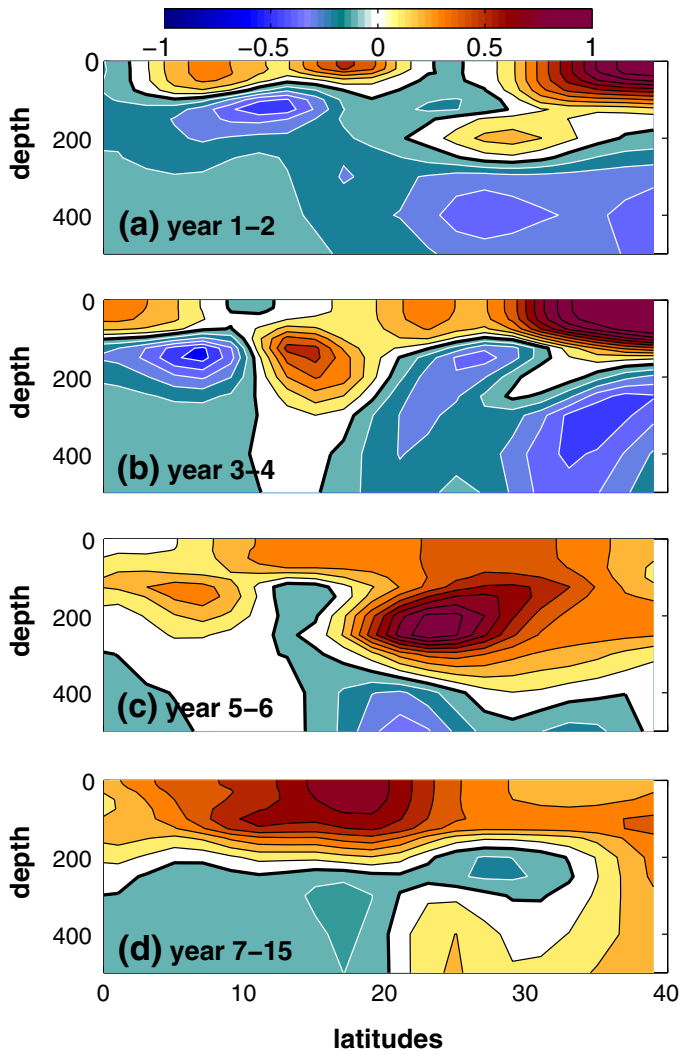

Fig. 12 Temporal changes of the vertical sea water temperature $\left({ }^{\circ} \mathrm{C}\right)$ as a function of depth-latitudes in the upper eastern Pacific Ocean $\left(160^{\circ} \mathrm{W}-120^{\circ} \mathrm{W}\right)$ averaged over each positive PDO phase in the CTRL

extended to $5^{\circ} \mathrm{N}-30^{\circ} \mathrm{N}$, meanwhile from Fig. 11 we can see that the anomalous southwesterly winds and associated reduced surface heat flux from the sea surface to atmosphere are more significant over off-equatorial region. As a result of this, the winds-driven upwelling of the relative cold subtropical sea water into the tropical surface is less in this region, leading to a significant warming in the offequatorial region of the tropics during the following decade after the beginning of the positive PDO phases (Fig. 12bd), which is consistent to the significant positive offequatorial SSTAs seen in the composite SSTAs (Fig. 10e, f). Moreover some studies also pointed out that the SSTAs in the equatorial region (i.e., the ENSO) forces the PDO, but not the results of the PDO (e.g., Alexander et al. 2002; Newman et al. 2003).

\subsubsection{Contributions of the warming in the ETP to a stronger WPSH}

After investigating a possible mechanism of the summer warming in the ETP under positive PDO phases, we now turn our attention to the potential role of the positive SSTAs in the ETP for generating a strengthened WPSH. The warming in the tropical Indian Ocean and the tropical western Pacific have been suggested to play an integral part in the intensification and westward extension of the WPSH after the late 1970s (e. g. Hu 1997; Zhou et al. 2009a). Our results, on the other hand, based on both the observations and the CTRL simulation show a significant positive correlation between the WPSH strengthen and the SSTAs in the ETP (Fig. 10a, b). To identify possible contributions from SSTAs in the ETP to changes of the WPSH, we first compared the differences of the $500 \mathrm{hPa}$ GPH (Fig. 14) and meridionally averaged vertical velocities (Fig. 15) between the years of positive $\left(>0.1{ }^{\circ} \mathrm{C}\right)$ and negative (less than $-0.1^{\circ} \mathrm{C}$ ) SSTAs in the ETP. In order to exclude the potential effects from concurrent warming in the IWP, the overlapping years of warm/cold IWP were removed prior 

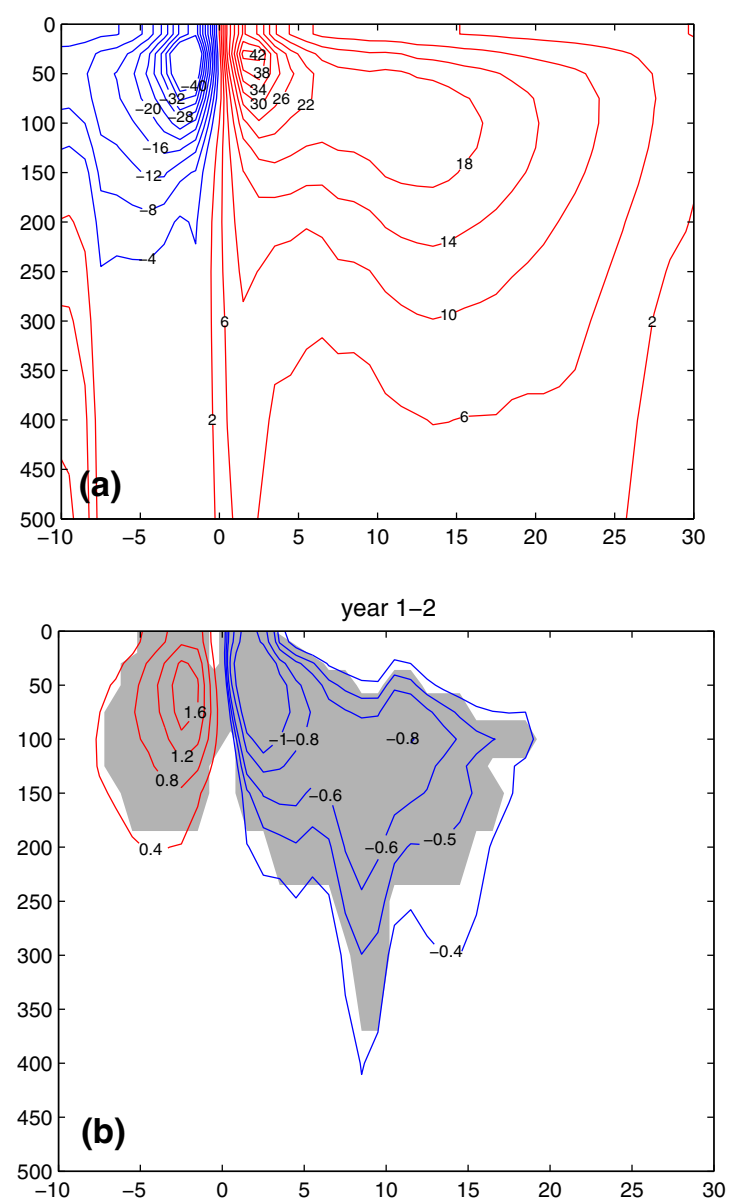

Fig. 13 Climatic averaged $\mathbf{a}$ and temporal changes $\mathbf{b}, \mathbf{c}$ of the ocean meridonal stream function as a function of depth-latitudes in the upper eastern Pacific Ocean during the positive PDO phases in the

to make the composites (Fig. 14a, b). The results based on both the observations (Fig. 14c) and model simulations (Fig. 14d) show clear increases of $500 \mathrm{hPa} \mathrm{GPH}$ over the western Pacific. For observed meridionally averaged velocities (Fig. 15a), anomalous ascending motions occur over $160^{\circ} \mathrm{W}-120^{\circ} \mathrm{W}$ and $20^{\circ} \mathrm{N}-25^{\circ} \mathrm{N}$ under the warm ETP. Associated with the anomalous ascending motion there are significant anomalous descending motions over the western Pacific $\left(120^{\circ} \mathrm{E}-140^{\circ} \mathrm{E}\right)$, which are reproduced in the CTRL simulation (Fig. 15b). Based on the results, it is thus hypothesized that the warming in the ETP may induce zonal atmospheric circulation anomalies over the subtropical-tropical Pacific, which subsequently contribute to an intensification of the WPSH.

To test the above hypothesis, we performed a pair of SST sensitivity experiments using CAM 3.0, including one control experiment and one experiment forced with prescribed SSTAs. In the control experiment, climatologically SSTs over 1938-1998 was used as the boundary conditions. During this period (1938-1998) the number of years with positive and negative PDO values, respectively, is

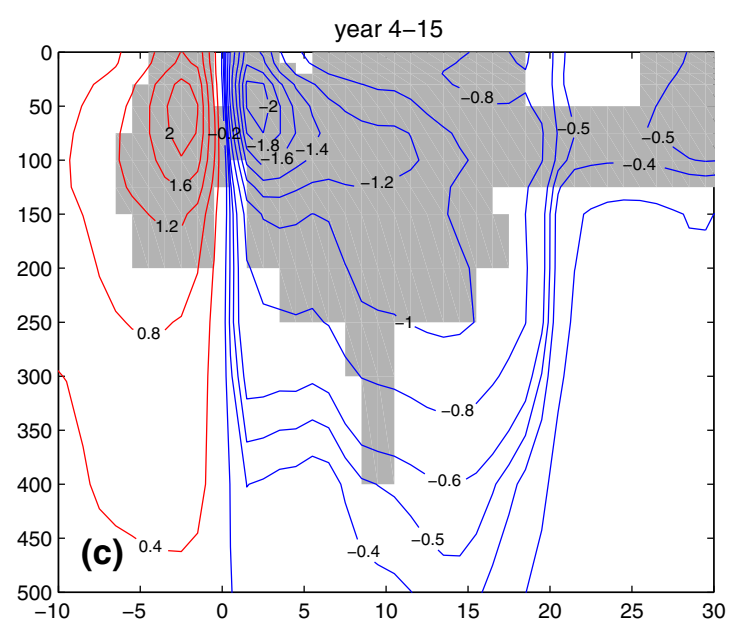

CTRL (Unit of the contours is Sv, $1 \mathrm{~Sv}=10^{6} \mathrm{~m}^{3} \mathrm{~s}^{-1}$ ). Anomalies in b and $\mathbf{c}$ with confidence levels exceeding $90 \%$ are shaded

about equal [31 years of negative PDO (1946-1975) and 31 years of the positive PDO (1938-1945 and 1976-1998)]. In the SSTA-forced experiment (SSTEXP), the SSTA-pattern found in the eastern Pacific (Fig. 16) during the positive PDO years were added to the climatologically SSTs to form the new surface boundary conditions. The differences of $500 \mathrm{hPa}$ GPH between the SSTEXP and control experiment were used to indentify the responses of the WPSH. Additionally, to further test the model responses, we carried one more pair of SST sensitivity experiments with the same way to set up SST boundary conditions but using a different AGCM, the ARPEGE (the atmosphere component of the BCM2).

From Fig. 16, in winter, clear horseshoe-like positive SSTAs pattern can be seen in the Eastern Pacific with a tropical extension to around $5^{\circ} \mathrm{N}$. In summer, the subtropical part of the horseshoe-like positive SSTAs is not significant. However, the positive SSTAs in the ETP remain significant, which can be explained by the weakened meridional circulation in the upper ocean as discussed previously. From Fig. 17, in summer our SSTAEXPs show 
Fig. 14 The composite SSTAs in a observations and $\mathbf{b}$ CTRL and $500 \mathrm{hPa}$ GPH (gpm) in the

c observations and d CTRL based on differences between phases of warm $\left(>0.1^{\circ} \mathrm{C}\right)$ and cold (less than $-0.1{ }^{\circ} \mathrm{C}$ ) SSTAs in the ETP. The areas of confidence level exceeding $95 \%$ are denoted shaded western Pacific in
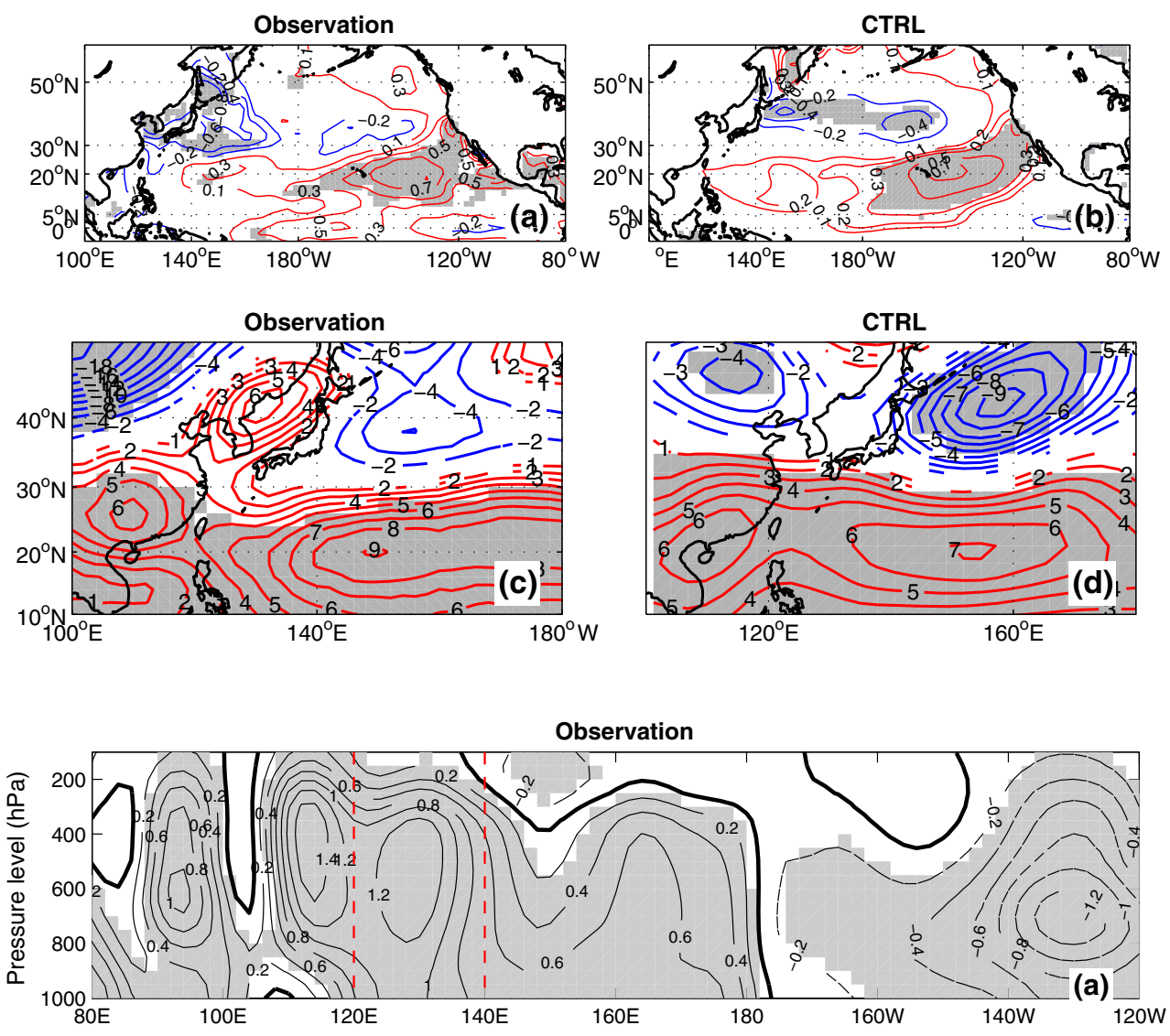

Fig. 15 Composites of vertical velocities $\left(10^{-4} \mathrm{hPa} \mathrm{s}^{-1}\right.$, averaged over $20^{\circ} \mathrm{N}-25^{\circ} \mathrm{N}$ ) in summer (JJA) as function of longitude-pressure level based on differences between warm $\left(>0.1^{\circ} \mathrm{C}\right.$ ) and cold (less than $0.1^{\circ} \mathrm{C}$ ) phases of SSTAs in the ETP in a observations over 1900-1999 and in b CTRL. The bold contours are for value of 0 . The negative (positive) value denotes the upward (downward) direction. The red dashed lines denote $120^{\circ} \mathrm{E}-140^{\circ} \mathrm{E}$. Differences with confidence levels exceeding $90 \%$ are shaded

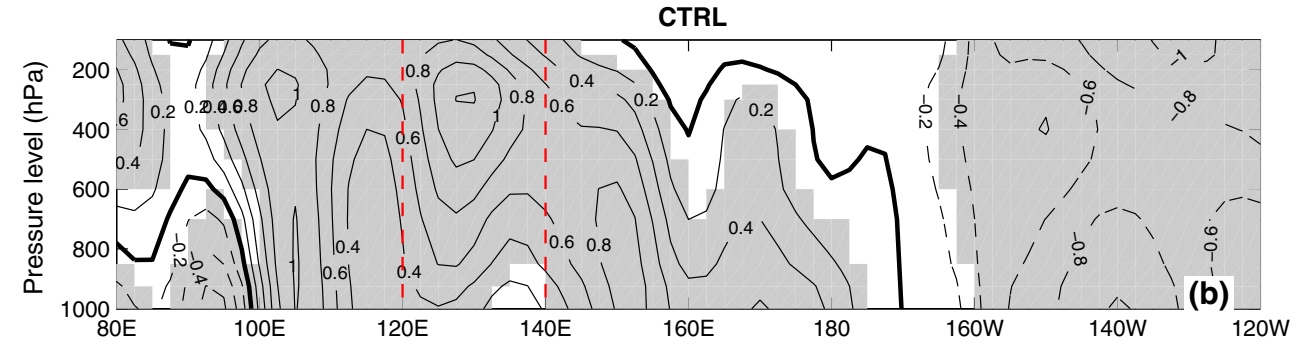

that this warming do force significant enhancement of the $500 \mathrm{hPa}$ GPH over the western Pacific Ocean covering most of the region south to $30^{\circ} \mathrm{N}$, with a centre of action located around $20^{\circ} \mathrm{N}\left(25^{\circ} \mathrm{N}\right)$ in CAM3.0 (ARPEGE), while it is located more over land in the observations. Also in the SSTEXPs the area of the increased $500 \mathrm{hPa}$ GPH are lager, with an extension to the North Central Pacific (especially for the CAM 3.0). Nevertheless significant increased $500 \mathrm{hPa}$ GPH in main domain (i.e., $120^{\circ} \mathrm{E}-140^{\circ} \mathrm{E}, 20^{\circ} \mathrm{N}-$ $25^{\circ} \mathrm{N}$ ) of the summer WPSH are obtained both in the CAM 3.0 and ARPEGE, indicating a contribution of the warmer SSTs in the ETP to intensification and southwestward extension of the WPSH.

The mechanism behind these responses may be explained by the systematic changes in the zonal atmospheric circulation. From Fig. 18, significant anomalous convergence winds at the $850 \mathrm{hPa}$ (Fig. 18c, d) and divergence winds at the $200 \mathrm{hPa}$ (Fig. 18a, b) can be found exactly over the warming boundary in the ETP in summer (Fig. 16c). The results indicate that the increased heating due to the warming in the ETP can generate substantial significant ascending motions over this region in the SSTEXP, it can been further found in the anomalous vertical velocities (Fig. 19a, b). Associated with these anomalous convergence and ascending over the ETP, opposite divergent winds at 850 and $200 \mathrm{hPa}(\mathrm{F})$ are found over the Western Pacific (Fig. 18), pointing to anomalous descending motions over the Western Pacific with westward extension to $100^{\circ} \mathrm{N}$ (Fig. 19) for the mass balance. These responses of the vertical motions to the positive SSTAs boundary condition in the SSTEXP indicate a weakened walker cell-like atmospheric circulation over the Pacific, corresponding to the enhancements of the $500 \mathrm{hPa}$ GPH (Fig. 17). 

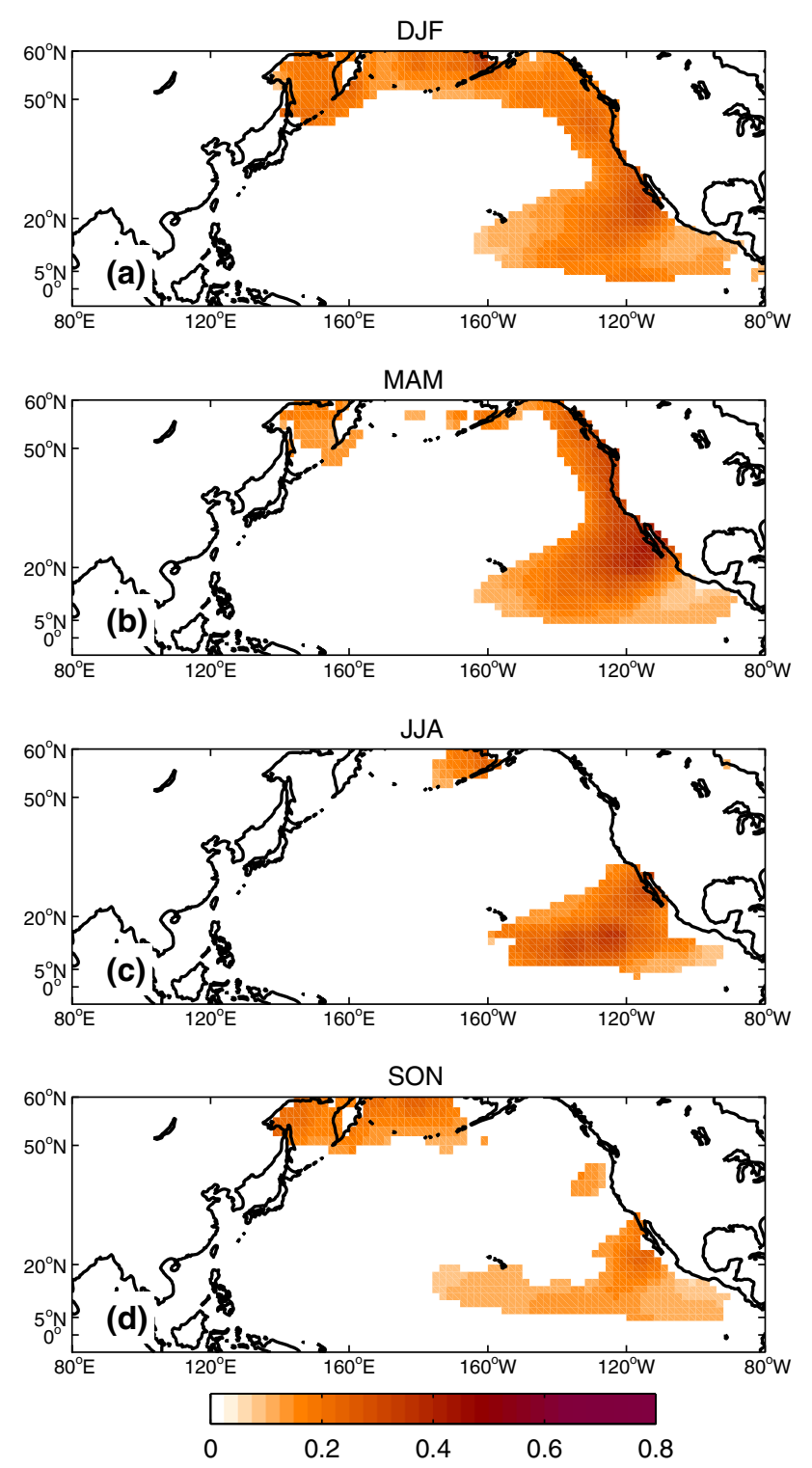

Fig. 16 Seasonal mean of winter (a, DJF)-spring (b, MAM)-summer (c, JJA)-fall (d, SON) of the monthly SSTAs $\left({ }^{\circ} \mathrm{C}\right)$ used to set up the surface boundary conditions in the SSTEXPs

\section{Discussion}

The mechanisms for the changes in summer precipitation over East China are complex. Previous statistical studies (e.g., Ma 2007) have shown a close linkage between the positive PDO and droughts in China. More specifically the positive phases of PDO generally corresponds to warm periods, with less precipitation and drought in North China, and vice versa. Other studies have also shown a robust relationship between a positive PDO and a downward trend in the summer precipitation over North China (Yang and Lau 2004) or a weakened EASM since late 1970s (Li et al. 2010). Moreover recent studies (Zhu et al. 2011) have documented that the summer precipitation pattern over East China has recently changed, with decreased precipitation over the YRV region and increased precipitation over the Huanghuai-River region $\left(32^{\circ} \mathrm{N}-36^{\circ} \mathrm{N}\right.$ and $110^{\circ} \mathrm{E}-$ $121^{\circ} \mathrm{E}$, in the central part of North China) during 2002-2008 relative to 1979-1999. They suggested that the observed recent negative PDO (2002-2008) induced a warming over the Lake Baikal and then a weakened meridional thermal gradient between $32^{\circ} \mathrm{N}$ and $42^{\circ} \mathrm{N}$. As a result, the moisture transports away from Huanghuai-River region was decreased, which subsequently caused the summer precipitationto increase in this region. However, a more recent study found a strengthened rather than weakened meridional thermal gradient between $32^{\circ} \mathrm{N}$ and $42^{\circ} \mathrm{N}$ in $\mathrm{N} 1$ as compared to $\mathrm{P} 1$ and $\mathrm{P} 2$ ( $\mathrm{Yu}$ 2013). A close examination of the water vapor fluxes in the present study suggest that a stronger WPSH is likely to have played a dominant role in the drought over North China by blocking the northward water vapor transports into this region: significant positive correlations were found between vertical integrated moisture content and the WPSH over the low reaches of the YRV region, while negative correlations were found over North China (Fig. 20). In addition, the integrated northward transports of moisture flux across the $30^{\circ} \mathrm{N}$ latitude section were found to be anti-correlated with changes in the WPSH intensity (Fig. 21).

It should, however, be pointed out that other studies have shown that the warming in the IWP could have caused the strengthening or western extension of the WPSH after the late 1970s through the enhancement of the Hadley Cell (Hu 1997) or by the modulation from an ENSO/Gill-type response (Zhou et al. 2009a). Hu (1997) also showed the positive correlations between SSTAs in the eastern tropical Pacific Ocean and the WPSH strength, so the important role of the ETP region for the WPSH has been noted before. In the present study this concept is taken a bit further using idealized sensitivity experiments in combination with analyses of observations and a multicentury climate model simulation to show a substantial contribution of the SSTAs in the ETP to changes of the WPSH. Our study can not determine which warming in the IWP or ETP was more important for the intensification of the WPSH, but suggests that the warming in the ETP can give rise to a strengthening of the WPSH on decadal time scales by causing anomalous zonal atmospheric circulation over the western Pacific Ocean. A recent study (Qian and Zhou 2013) for North China focusing on the multidecadal variations in aridity and its relationship to PDO during 1900-2010 found a weakened land-sea thermal contrast as a result of the warmer SSTAs in the tropical western Pacific and cooling in the $40^{\circ} \mathrm{N}-60^{\circ} \mathrm{N}$ indicated by the differences between positive and negative PDO phases ( $\mathrm{P} 1$ and $\mathrm{P} 2$ miuns N1). The resulting weakening of the EASM 

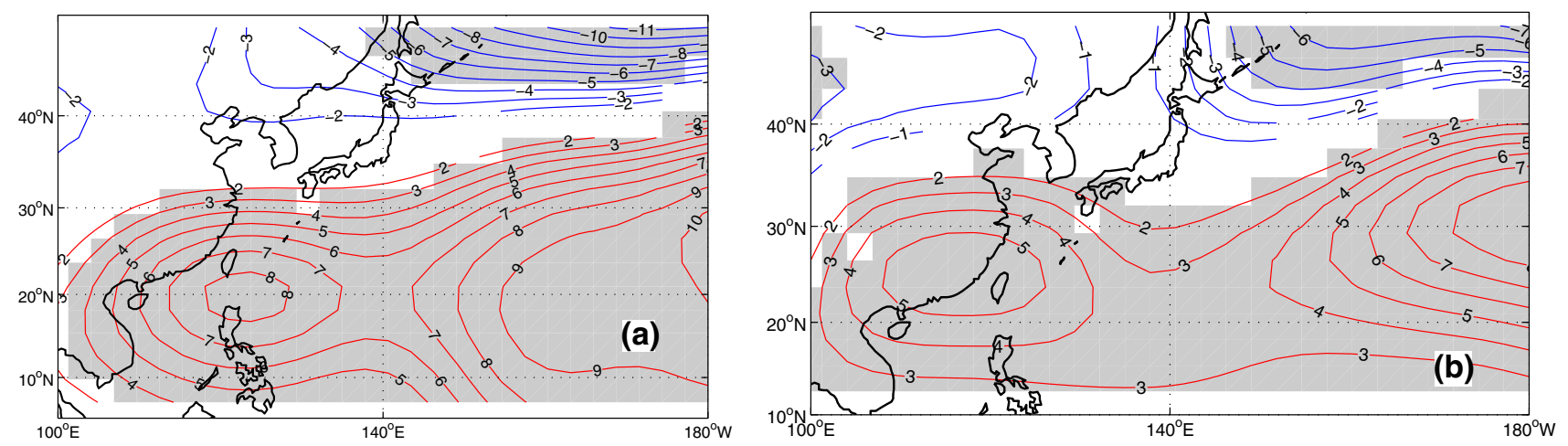

Fig. 17 The differences of $500 \mathrm{hPa}$ GPH (gpm) between SSTEXP and control experiment in a CAM 3.0 and b ARPEGE AGCM. Differences with confidence levels exceeding $90 \%$ are shaded
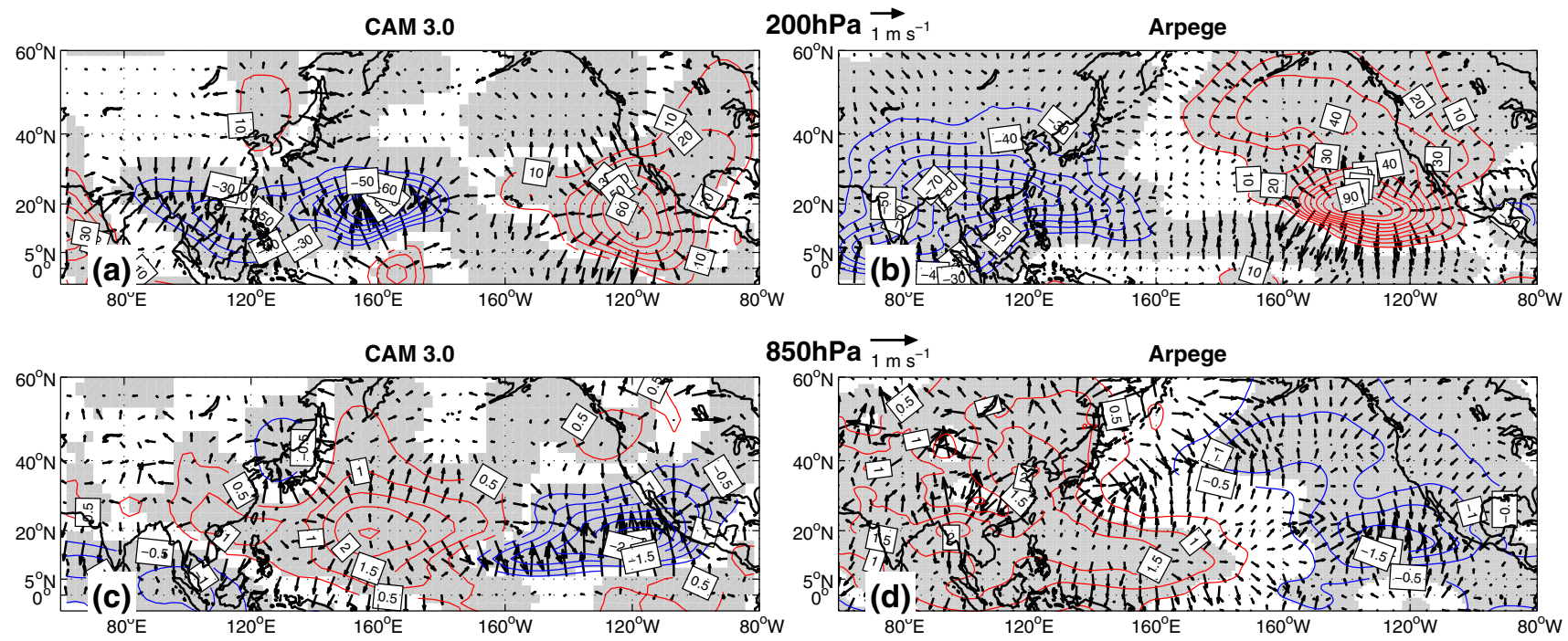

Fig. 18 The differences of velocity potential (contour lines, $10^{6} \mathrm{~m}^{2}$ $\left.\mathrm{s}^{-1}\right)$ and divergent component of the wind vectors $\left(\mathrm{m} \mathrm{s}^{-1}\right)$ at a $200 \mathrm{hPa}$ and $\mathbf{c} 850 \mathrm{hPa}$ between SSTEXP and control experiment in

CAM 3.0. $\mathbf{b}$ and $\mathbf{d}$ Same as a and $\mathbf{c}$ but for ARPEGE. Differences with confidence levels exceeding $90 \%$ are shaded

was highlighted as one of their suggested mechanisms for the drought over North China in the two positive PDO phases. However, in the present study we show that in the earlier positive PDO (P1), the SSTs in the tropical western Pacific were lower than N1 (Fig. 10c), but meanwhile we can find significant warming in the ETP in P1 and also a stronger WPSH in this period (Fig. 9a). Thus the forcing of the summer warming in the ETP may play a necessary role in causing an intensification of the WPSH, which subsequently blocks the northward water vapor transports into this region (Figs. 20, 21) resulting in drought over North China.

This study also suggests that the summer warming over the ETP region can originate from the eastern subtropical horseshoe-like warming found in winter. The associated mechanism involves a weakened ocean meridional circulation and a fast WES process, where the latter works annually in most years during the positive PDO period. Some other studies (i.e., Vimont et al. 2001) have also suggested that extratropical-tropical teleconnections could act as a conveyor to transmit subtropical climatic anomalies to the tropics. Our study also did not address what mechanisms drive the North Pacific decadal climate changes, but addressed the mechanism for the summer warming in the ETP after the positive PDO has been set up in winter. Thus, our study does not exclude a substantial influence from the tropics on the North Pacific (e.g., Alexander et al. 2002; Deser et al. 2004) or on the PDO (Newman et al. 2003).

Finally, Wang et al. (2013) also addressed potential causes for the observed YFND-pattern during 1976-1990s relative to 1958-1975. They carried out four sets of 
Fig. 19 The differences of vertical velocities $\left(10^{-4} \mathrm{hPa} \mathrm{s}^{-1}\right.$, averaged over $20^{\circ} \mathrm{N}-25^{\circ} \mathrm{N}$ ) between SSTEXP and control experiment in a CAM 3.0 and b ARPEGE AGCM. Differences with confidence levels exceeding $90 \%$ are shaded
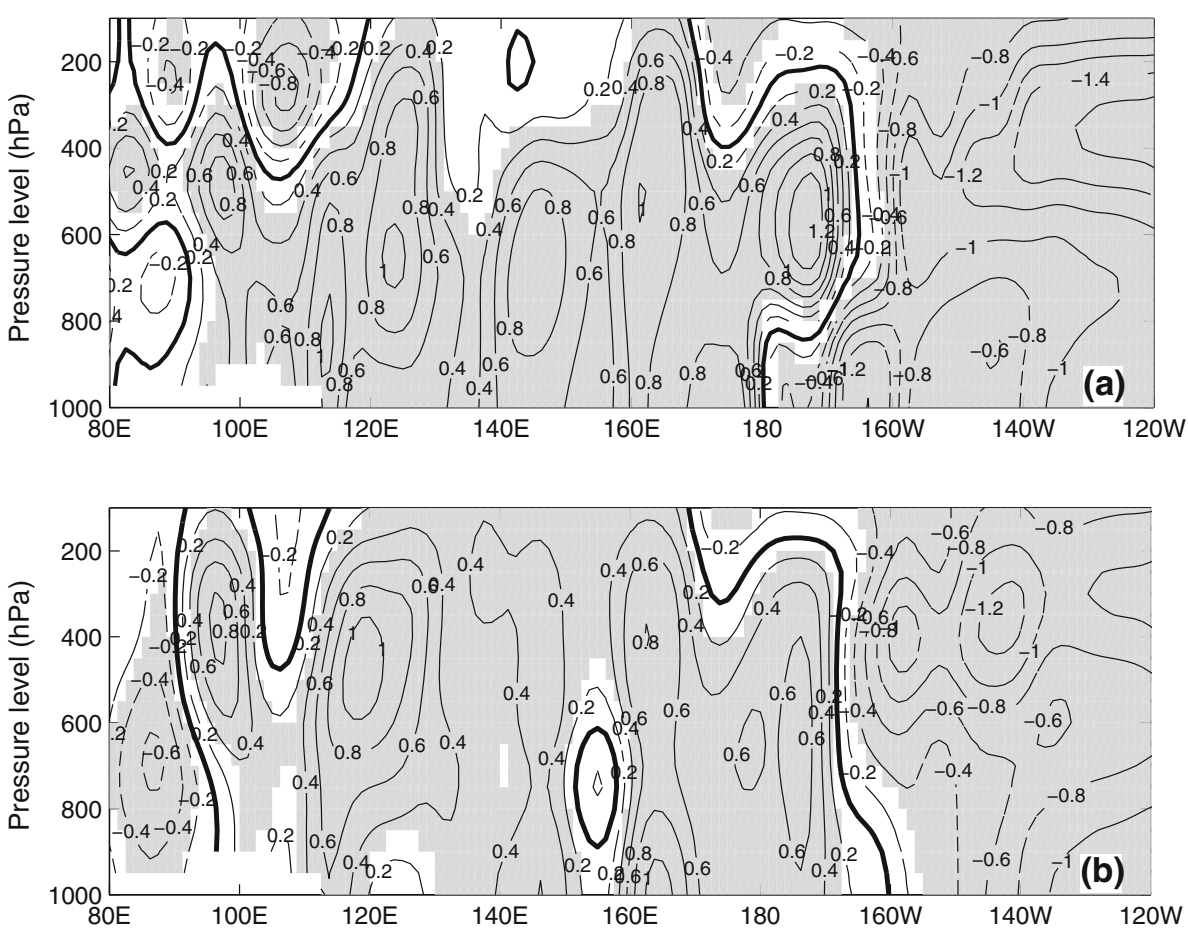

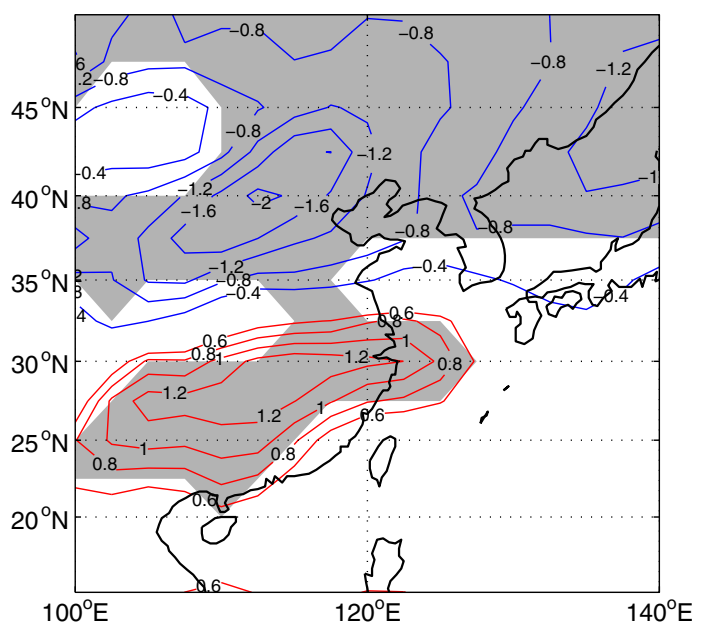

Fig. 20 Regression map of vertical integrated (from 1,000 to $200 \mathrm{hPa}$ ) moisture content against WPSH strength index in observations. Regressions with confidence levels exceeding $90 \%$ are shaded

historical simulations including various combinations of natural and anthropogenic forcings. Their results show that only the all-forcing simulations, where both natural forcing agents (solar variations and volcanoes) and anthropogenic forcing agents (well-mixed greenhouse gases and tropospheric sulphate aerosols) are incorporated into the model, are able to successfully reproduce the YFND pattern after the 1970s. They therefore suggested that the late twentieth century interdecadal summer precipitation shift was mainly caused by the combined effect of increasing global greenhouse gases and regional aerosol emissions over China. However, their analysis was restricted to the period 1958-1995, while in this study it is shown that such summer precipitation distribution shift can also be found between the early positive (1925-1946) and negative (1947-1976) phases of the PDO. Also, a recent analysis of CMIP5 models response (Song et al. 2014) found that the GHG drives a stronger E. Asian summer monsoon while the aerosol forcing drives a weaker E. Asian summer monsoon. Moreover, the observed distribution of recent summer precipitation over East China during 2002-2008 (when the PDO has been in its negative phase) relative to 1979-1999 (P1) shows more precipitation in North China and less in the YRV region (Zhu et al. 2011), which is in fact an opposite pattern to the YFND. This could therefore implicate a recovery of the EASM related to the PDO (Li et al. 2012a, b). Thus, this anti-correlation between the PDO and the south-north shift of summer precipitation pattern over eastern China may provide further observed evidences for the mechanism put forward in this study, basically suggesting that most of the decadal summer precipitation changes over eastern Asia are related to the naturally varying PDO.

\section{Summary and final remarks}

In this study we investigated the modulation of the PDO on summer precipitation over East China based on observations and a 600-year model simulation. In addition two 
Fig. 21 The decadal time sires of standard vertical integrated northward moisture transports across latitude of $30^{\circ} \mathrm{N}$ between $105^{\circ} \mathrm{E}$ and $120^{\circ} \mathrm{E}$ and WPSH index in observations

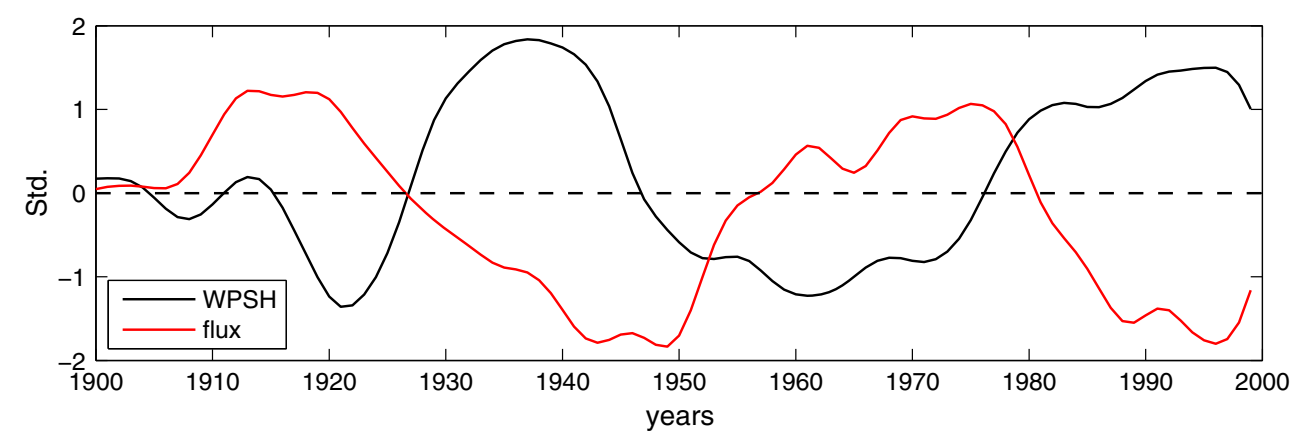

SSTA-forced AGCM experiments were conducted to study the potential mechanism behind the linkage between the PDO and summer climate of the East China. The main findings are summarized as follows:

1. Based on the analysis of the observations, significant correlations are found between the PDO and the changes of the summer precipitation over East China over the past century. We find that when PDO is in its positive phases, the summer precipitation over YRV region is increased, while it is decreased over North China. This results in a "South flood and North Drought" pattern over East China.

2. Similar correlations over East China is well reproduced in a long-term run of the fully coupled BCM model, providing further evidences for the linkage between PDO and summer precipitation.

3. Based on both diagnostics from observations and model output from BCM, we suggest that the mechanism behind the linkage can be summarized as follows: (1) during positive phases of the PDO, the winter warming in the eastern subtropical Pacific propagate to the eastern tropical Pacific Ocean in summer through a weakened ocean meridional circulation in the upper Eastern Pacific Ocean on decadal time scale and repeated coupled annual winds-evaporation-SSTs feedback process during the positive PDO years; (2) the warming in the eastern subtropical Pacific further generates a strengthened WPSH, which restricts the northward water vapor transports into North China and cause increased water moisture over the YRV region. This ultimately results in a "South flood and North Drought" pattern over East China.

4. The contribution of the warming in the ETP to a stronger WPSH is evaluated by two SSTA-forced AGCM experiments. These experiments further highlight the important role of the SSTAs in the ETP in modulating the decadal variability of the WPSH.

Acknowledgments This work is supported by Research Council of Norway through the DecCen project (Exploring Decadal to Century Scale Variability and Changes in the East Asian Climate during the last Millennium). It is a contribution to the Centre for Climate Dynamics and the Bjerknes Centre for Climate Research in Bergen, Norway. The authors are grateful for helpful discussions with Dr. Martin King and with Dr. Thomas Toniazzo about the WES process and Dr. Zhongshi Zhang about the SSTA-forced experiments by CAM 3.0.

Open Access This article is distributed under the terms of the Creative Commons Attribution License which permits any use, distribution, and reproduction in any medium, provided the original author(s) and the source are credited.

\section{References}

Alexander MA, Blade I, Newman M, Lanzante JR, Lau N, Scott J (2002) The atmospheric bridge: the influence of ENSO teleconnections on air-sea interaction over the global oceans. J Clim 15:2205-2231

Allan R, Ansell T (2006) A new globally complete monthly gridded mean sea level pressure dataset (HadSLP2): 1850-2004. J Clim 19:5816-5842

Barnett TP, Pierce DW, Latif M, Dommenget D, Saravanan R (1999) Interdecadal interactions between the tropics and midlatitudes in the Pacific basin. Geophys Res Lett 26:615-618

Bleck R, Smith LT (1990) A wind-driven isopycnic coordinate model of the north and equatorial Atlantic-Ocean. 1. Model development and supporting experiments. J Geophy Res 95:3273-3285

Bleck R, Rooth C, Hu D, Smith LT (1992) Salinity-driven thermocline transients in a wind-forced and thermohaline-forced isopycnic coordinate model of the North-Atlantic. J Phys Oceanogr 22:1486-1502

Collins WD, Rasch PJ, Boville BA et al (2004) Description of the NCAR community atmosphere model (CAM 3.0). Technical report, National Center for Atmospheric Research, Boulder, Colorado, http://www.cesm.ucar.edu/models/atm-cam

Déqué M, Dreveton C, Braun A, Cariolle A (1994) The ARPEGE/Ifs atmosphere model-a contribution to the French Community climate modeling. Clim Dyn 10:249-266

Deser C, Phillips AS, Hurrell J (2004) Pacific interdecadal climate variabolity linkage between the tropics and the North Pacific during boreal winter since 1900. J Clim 17:3109-3124

Ding Y, Wang ZY, Sun Y (2008) Inter-decadal variation of the summer precipitation in East China and its association with decreasing Asian summer monsoon. Part I: observed evidences. Int J Clim. doi:10.1002/joc.1615

Furevik T, Bentsen M, Drange $\mathrm{H}$ et al (2003) Description and evaluation of the Bergen climate model: ARPEGE coupled with MICOM. Clim Dyn 21:27-51 
Gong D (2007) Climate of China. In: Wang S, Li W (eds) Climate disasters. China Meteor Press, Beijing, pp 138-176

Gong D, Ho CH (2002) Shift in the summer precipitation over the Yangtze River valley in the late 1970s. Geophys Res Lett 29. doi:10.1029/2001GL014523

Gong D, Wang S (2000) Experiments on the reconstruction of historical monthly mean northern hemispheric $500 \mathrm{hPa}$ height from surface data (in Chinese). J Trop Meteorol 16(2):148-154

Gong D, Drange H, Gao Y (2007) Reconstruction of northern hemisphere $500-\mathrm{hPa}$ geopotential heights back to the late 19th century. Theor Appl Climatol 90:83-102. doi:10.1007/s00704006-0271-3

Gu D, Philander SGH (1997) Interdecadal climate fluctuations that depend on exchanges between the tropics and extratropics. Science 275:805-807

He X, Gong D (2002) Interdecadal change in western Pacific subtropical high and climatic effects. J Geogr Sci 12(2):202-209

$\mathrm{Hu} \mathrm{Z} \mathrm{(1997)} \mathrm{Interdecadal} \mathrm{variability} \mathrm{of} \mathrm{summer} \mathrm{climate} \mathrm{over} \mathrm{East}$ Asia and its association with $500 \mathrm{hPa}$ height and global sea surface temperature. J Geophys Res 102(D16):19403-19412. doi:10.1029/97JD01052

$\mathrm{Hu}$ Z, Yang R (2003) Long-term climate variations in China and global warming signals. J Geophys Res 108(D19):4614. doi:10. 1029/2003JD003651

Johnny C, Zhou W (2005) PDO, ENSO and the early summer monsoon precipitation over south China. Geophys Res Lett 32. doi:10.1029/2004GL022015

Latif M, Barnett TP (1994) Causes of decadal climate variability over the north Pacific and North America. Science 266:634-637

Lau K, Weng H (2001) Coherent modes of global SST and summer precipitation over China: an assessment of the regional impacts of the 1997-98 El Niño. J Clim 14:1294-1308

Levitus S, Boyer TP (1994) World ocean atlas 1994. In: Temperature, NOAA Atlas NESDIS 4, vol 4. U.S. Department of Commerce, Washington DC, p 117

Li L, Wang B, Zhou T (2007) Contributions of natural and anthropogenic forcing to the summer cooling over East China: an AGCM study. Geophy Res Lett 34:L18807. doi:10.1029/ 2007GL030541

Li H, Dai A, Zhou T (2010) Responses of East Asian summer monsoon to historical SST and atmospheric forcing during 1950-2000. Clim Dyn 34:501-514

Li H, Zhou T, Zhu Y, Lin Y (2012a) The strengthening East Asia summer monsoon since the early 1990s. Chin Sci Bull 57:1553-1558. doi:10.1007/s11434-012-4991-8

Li J, Wu Z, Jiang Z, He J (2012b) Can global warming strengthen the East Asian summer monsoon? J Clim 23:6696-6705

Ma Z (2007) The interdecadal trend and shift of dry/wet over the central part of northern China and their relationship to the Pacific Decadal Oscillation (PDO). Chin Sci Bull 52(15):2130-2139

Mantua NJ, Hare SR, Zhang Y, Wallace JM, Francis R (1997) A Pacific interdecadal climate oscillation with impacts on salmon production. Bull Am Meteorol Soc 78:1069-1079

Menon S, Hansen J, Nazarenko L, Luo Y (2002) Climate effects of black carbon aerosols in China and India. Science 297:2250-2253

Mitchell TD, Jones PD (2005) An improved method of constructing a database of monthly climate observations and associated highresolution grids. Int J Clim 25:693-712

Mu Q, Wang S, Zhu J, Gong D (2001) Variations of the western Pacific subtropical high in summer during the last hundred years. Chin J Atmos Sci 25:787-797 (in Chinese)

Newman M, Compo GP, Alexander MA (2003) ENSO-forced variability of the Pacific decadal oscillation. J Clim 16:3853-3857

Otterå OH, Bentsen M, Bethke I, Kvamsto NG (2009) Simulated preindustrial climate in Bergen Climate Model (version 2) model description and large-scale circulation features. Geosci Model Dev 2:197-212

Qian C, Zhou T (2013) Multidecadal variability of North China aridity and its relationship to PDO during 1900-2010. J Clim 27(3):1210-1222

Salas Mélia D (2002) A global coupled sea ice-ocean model. Ocean Model 4:137-172

Schneider U, Becker A, Finger P, Meyer-Christoffer A, Rudolf B, Ziese M (2011) GPCC full data reanalysis version 6.0 at $1.0^{\circ}$ : monthly land-surface precipitation from rain-gauges built on GTS-based and historic data. doi:10.5676/DWD_GPCC/FD_M_ V6_100

Smith TM, Reynolds RW, Peterson TC, Lawrimore J (2008) Improvements to NOAA's historical merged land-ocean surface temperature analysis (1880-2006). J Clim 21:2283-2296

Song F, Zhou T, Qian Y (2014) Responses of East Asian summer monsoon to natural and anthropogenic forcings in the 17 latest CMIP5 models. Geophys Res Lett 41. doi:10.1002/ 2013GL058705

Sui CH, Chung PH, Li T (2007) Interannual and interdecadal variability of the summertime western North Pacific high. Geophys Res Lett 34:L11701

Terray L, Thual O, Belamari S, Déqué M, Dandin P, Delecluse P, Levy C (1995) Climatology and interannual variability simulated by the ARPEGE-Opa coupled model. Clim Dyn 11:487-505

Vimont DJ, Wallace JM, Battisti DS (2001) Footprinting: a seasonal connection between the midlatitudes and tropics. Geophys Res Lett 28:3923-3927

Wang $\mathrm{H}$ (2001) The weakening of the Asian monsoon circulation after the end of 1970's. Adv Atmos Sci 18:376-385

Wang B, Wu R, Fu X (2000) Pacific-East Asian teleconnection: how does ENSO affect East Asian climate? J Clim 13:1517-1536

Wang T, Wang H, Otterå OH, Suo L, Furevik T, Gao Y, Yu L (2013) Anthropogenic forcing of shift in precipitation in East China in late 1970s. Atmos Chem Phys 13:11997-12032

$\mathrm{Wu}$ B, Zhou $\mathrm{T}$ (2008) Oceanic origin of the interannual and interdecadal variability of the summertime western Pacific subtropical high. Geophys Res Lett 35:L13701

Wu R, Hu Z, Kirtman B (2003) Evolution of ENSO-related precipitation anomalies in East Asia. J Clim 16(22):3742-3758

Wu L, Liu Z, Li C, Sun Y (2007) Extratropical control of recent tropical Pacific decadal climate variability: a relay teleconnection. Clim Dyn 28:99-112

Xu Q (2001) Abrupt change of the mid-summer climate in central east China by the influence of atmospheric pollution. Atmos Environ 35:5029-5040

Yang F-L, Lau K-M (2004) Trend and variability of China precipitation in spring and summer: linkage to sea surface temperatures. Int J Climatol 24:1625-1644

Yu L (2013) Potential correlation between the decadal East Asian summer monsoon variability and the Pacific decadal oscillation. Atmos Ocean Sci Lett 6(5):394-397

Yu R, Zhou T (2007) Seasonality and three-dimensional structure of the interdecadal change in East Asian monsoon. J Clim 20:5344-5355

Yu R, Wang B, Zhou T (2004) Tropospheric cooling and summer monsoon weakening trend over East Asia. Geophys Res Lett 28:L22212. doi:10.1029/2004GL021270

Zhang Y, Wallace JM, Battisti D (1996) ENSO-like interdecadal variability: 1900-93. J Clim 10:1004-1020

Zhou T, Yu R, Zhang J, Drange H, Cassou C, Deser C, Hodson D, Sanchez-Gomez E, Li J, Keenlyside N, Xin X, Okumura Y (2009a) Why the Western Pacific subtropical high has extended westward since the late 1970s. J Clim 22:2199-2215

Zhou T, Gong D, Li J, Li B (2009b) Detecting and understanding the multi-decadal variability of the East Asian summer monsoon- 
recent progress and state of affairs. Meteorol Zeitschrift 18:455-467

Zhou T, Song F, Lin R, Chen X, Chen X (2013) Explaining extreme events of 2012 from a climate perspective. Bull Am Meteorol Soc 94:S1-S74. doi:10.1175/BAMS-D-13-00085.1
Zhu Y, Wang H, Zhou W, Ma JH (2011) Recent changes in the summer precipitation pattern in East China and the background circulation. Clim Dyn 36:1463-1473 